\title{
CARTOGRAFÍA DE LA VULNERABILIDAD DEL TERRITORIO FRENTE AL RIESGO DE INUNDACIÓN. PROPUESTA ADAPTADA A LA DIRECTIVA EUROPEA DE INUNDACIONES Y NORMATIVAS DERIVADAS
}

\author{
M.J. Perles Roselló ${ }^{1}$ \\ J.F. Sortino Barrionueno ${ }^{1}$ \\ F. Cantarero Prados ${ }^{2}$ \\ 1. Departamento de Geografía. Universidad de Málaga \\ 2. Escuela Nacional de Estudios Superiores - UNAM \\ mjperles@uma.es, francis.sortino@gmail.es, fjcantarero@enes.unam.mx
}

\section{RESUMEN}

En el artículo se aporta una propuesta de catálogo cartográfico de vulnerabilidad a escala intra-municipal, adaptado a los requerimientos de la normativa europea, a los Planes de Gestión del Riesgo y a los Planes de Ámbito Local a aplicar en las ARPS (Áreas de Riesgo Potencial Significativo). Se reflexiona sobre el concepto de vulnerabilidad frente al riesgo, y se puntualizan aspectos cuya definición imprecisa o dispersa dificulta la elaboración de indicadores y cartografías de vulnerabilidad consensuadas. Se adjuntan ejemplos de la cartografía propuesta aplicados al área de inundación del río Guadalhorce (Málaga).

Palabras clave: cartografía vulnerabilidad del territorio, vulnerabilidad social, riesgo inundación, Planes Gestión del riesgo, medidas mitigación del riesgo.

\section{ABSTRACT}

The article provides a proposal for a mapping vulnerability catalogue adapted to the requirements of implementation of measures in the framework of european risk management, and more specifically, to those expressed in the risk management plans in the ARPS (Potential Significant Risk Areas) through local plans. The paper ponders the concept of

Fecha de recepción: abril 2016.

Fecha de aceptación: diciembre 2016. 
vulnerability to risk, and point out inaccurate aspects that hinder the development of consensus-based vulnerability mapping. Examples of the proposed mapping applied to the area of flooding of the river Guadalhorce (Málaga) are attached.

Keywords: territorial vulnerability, social vulnerability and risk mapping flood, risk, risk mitigation action plans management

\section{INTRODUCCIÓN Y OBJETIVOS}

Las metodologías para evaluar la vulnerabilidad de los elementos expuestos frente al riesgo de inundación están adquiriendo una consideración creciente en el ámbito aplicado, al hilo de la obligatoriedad de incluir cartografías de vulnerabilidad en documentos normativos de distintas escalas. Las fases de elaboración de mapas de peligrosidad y de riesgo, como la de elaboración de Planes de Gestión del Riesgo previstas en la Directiva Europea de Inundaciones, en el R.D. 903/2010 y en las respectivas normativas autonómicas equivalentes, requieren la elaboración de cartografías de vulnerabilidad frente a la inundación. Esta cartografía será igualmente necesaria a la hora de aplicar las medidas de mitigación ${ }^{1}$ sobre las distintas ARPS ${ }^{2}$ a través de los Planes de Actuación de Ámbito Local.

Sin embargo, el relativo auge que la noción de vulnerabilidad está experimentando en las normativas de prevención, no ha sido precedido, como sería de desear, por un desarrollo riguroso del concepto a nivel de investigación, ni de la propuesta de métodos de cartografía precisos que habiliten la potencialidad del concepto como herramienta para la gestión de la inundación. Tampoco los textos a nivel normativos son muy exigentes sobre la cuestión, de tal modo que, para elaborar mapas de vulnerabilidad se proponen indicadores muy laxos de exposición ${ }^{3}$ de la población y de los bienes, y del valor económico de la pérdida, sin que lleguen a especificarse orientaciones para la evaluación de la vulnerabilidad. Ante esta circunstancia, es fácil prever que, a la hora de realizar las cartografías, cada técnico se regirá por su propio criterio, con las consiguientes consecuencias de dispersión, no-comparación, o falta de precisión conceptual.

En este contexto, el objetivo último del artículo es la presentación de una propuesta cartográfica para la evaluación de la vulnerabilidad del territorio frente a la inundación. Se pretende que los mapas propuestos recojan la casuística imprescindible para analizar la vulnerabilidad del territorio frente a la inundación en el marco de aplicación de los Planes de Gestión del Riesgo, y que sean útiles para identificar las medidas de mitigación necesarias en cada caso.

1 Medidas de mitigación: conjunto de medidas orientadas a la mitigación de las consecuencias del riesgo. Se agrupan en medidas preventivas, paliativas y rehabilitadoras, actuando respectivamente en las fases previa, simultánea y posterior a la producción de la catástrofe (Pita, 1999).

2 Áreas de Riesgo Potencial Significativo.

3 Exposición: conjunto de bienes a preservar que pueden ser dañados por la acción de un peligro (Olcina y Ayala, 2002). La Directiva 2007/60/CE sobre el riesgo de inundación especifica como bienes a preservar la salud y vida humana, el medio ambiente, el patrimonio cultural, la actividad económica y las infraestructuras. 
Para la consecución de este objetivo último, ha sido necesario abordar los siguientes objetivos parciales:

1. Análisis de los requerimientos expresados en el contexto normativo a distintas escalas (comunitario, estatal, autonómico y local) en relación con la cartografía de vulnerabilidad frente a la inundación.

2. Reflexión, a partir de antecedentes teóricos y aplicados, y de los propios requerimientos normativos, sobre la noción de vulnerabilidad frente a la inundación; observación de incoherencias e imprecisiones que contribuyen a la dispersión del concepto y de los métodos de evaluación cartográfica asociados.

3. Conceptuación de la noción de vulnerabilidad del territorio frente al riesgo de inundación. Estructuración y precisión de matices en el concepto.

4. Identificación de problemas concretos relacionados con la vulnerabilidad en las distintas fases de inundación (pre-emergencia, emergencia y normalización), a partir del análisis de los procesos territoriales subyacentes a la generación de la vulnerabilidad, y del estudio empírico de eventos precedentes.

5. Propuesta de un catálogo cartográfico adaptado a los distintos problemas-soluciones de vulnerabilidad identificados.

6. Aplicación de la propuesta cartográfica al área de inundación del Bajo Guadalhorce para obtener ejemplos cartográficos ilustrativos.

\section{ANTECEDENTES Y BASES CONCEPTUALES DE LA PROPUESTA CARTOGRÁFICA}

\section{II.1. Evolución del concepto de vulnerabilidad. Antecedentes teóricos}

Los antecedentes teóricos sobre la noción de vulnerabilidad social ${ }^{4}$ frente al riesgo son muy abundantes en la literatura, aunque presentan problemas de disparidad e imprecisión a la hora de fijar los contenidos del concepto. La noción de vulnerabilidad se ha ido desarrollando y centrando sucesivamente sobre los conceptos de exposición física, susceptibilidad, resiliencia, y más recientemente capacidad de lucha. En lo que se refiere a las distintas perspectivas con las que el concepto ha sido abordado a lo largo de su evolución Perles, (2010) resume como a partir de enfoques basados en la comprensión de la vulnerabilidad como exposición física frente al peligro ${ }^{5}$ (Alexander, 1993; D’Ercole, 1994; Bechler-Carmaux et al., 2000), se evolucionó, desde perspectivas procedentes de la economía política y la geografía radical a la búsqueda de una teoría social que explique la desigualdad frente a la catástrofe. Autores como Hewitt, Pelling, Smith y D’Keefe, (1980); Susman, O’Keefe y Wisner, (1983), Watts, (1983), Maskrey (1993), junto a Cannon (1994), Bankoof (2003), Blaikie et al. (1994) o Wisner et al. (2004), son responsables del protagonismo de la componente social de la vulnerabilidad frente al riesgo. Esta tendencia ha tenido una gran resonancia en los estudios de vulnerabilidad en entornos menos desarrollados, como es el caso de América

4 Vulnerabilidad social: características de una persona o grupo de personas en términos de su capacidad para anticipar, gestionar, resistir o recuperarse del impacto de un riesgo (Blaikie et al., 1994).

5 Peligro: proceso o fenómeno de carácter natural o tecnológico que puede originar daños a la población, los bienes materiales o al medio ambiente natural (Olcina y Ayala, 2002). 
Latina, donde desde 1992 centran los trabajos de La Red (Lavell, 1994), con importantes aportaciones desde el ámbito de la sociología. La crítica a esta perspectiva se ha centrado en sus contenidos más teóricos que aplicados, y en la deslocalización de los problemas, la falta de anclaje con el territorio que acompaña al carácter más abstracto que geográfico con el que se abordan las dimensiones sociales del riesgo.

Un paso más avanzado lo aportan los enfoques holísticos (Cardona, 2003, Barbat et al. 2011, Carreño et al, 2014) y los más integradores, para los que espacio de producción del riesgo se considera un ámbito mixto, en el que interactúan factores naturales y artificiales tanto en la producción del riesgo como en la gravedad de las consecuencias. A esta visión han contribuido las aproximaciones contextuales al riesgo (Mitchel et al., 1989; Palm, 1990; Kirby, 1990; Ribas y Saurí, 1996; Saurí, 2004), y las relecturas de los planteamientos originales de la Escuela de Chicago que plantean el riesgo como un problema de adaptación de la sociedad al riesgo (Calvo, 2001). Los trabajos de Cutter (2003) dan un paso más en este sentido, para plantear su teoría del "lugar de riesgo". Según esta autora, los factores definidos por el "lugar", entendido como síntesis de elementos biofísicos y sociales, condicionan y construyen el riesgo en un determinado territorio. Cutter (2003), junto con autores como Smith (1994), Veyret, Boucher o Bonard (2005)), Calvo (2002), Ruiz (2011) y Perles (2008, 2010), apuestan por la comprensión del riesgo como un hecho territorial, entendido este como la síntesis de los aspectos físicos y humanos que condicionan el riesgo y el desastre. El enfoque utilizado en este artículo se fundamenta en la comprensión del riesgo como un proceso complejo de la relación sociedad-medio, y necesitado por ello de un enfoque holístico. A nuestro entender, como ya observara la perspectiva de la ecología humana, y autores como Calvo (2001) se trata de un fenómeno dependiente del grado de adaptación del patrón humano de uso del territorio al patrón de peligrosidad natural o artificial que el territorio presente. Por otra parte, resulta evidente que el grado de adaptación, tal y como han argumentado los teóricos de la dimensión más social de la vulnerabilidad, y de los enfoques contextuales del riesgo, depende en gran parte de aspectos conductuales de los distintos agentes sociales (percepción, información, organización, etc.) cuestiones que a su vez están orientadas por condicionantes económicos, ideológicos y políticos, por condicionantes técnicos y por modelos culturales y de producción y uso del entorno determinados socialmente. Todos estos condicionantes generan de forma subyacente el modelo de uso del territorio de una sociedad. El patrón territorial ${ }^{6}$ de uso del territorio, esto es, la distribución en el espacio de población, bienes y servicios territoriales, es la expresión física o material del modelo subyacente, de la relación que cada sociedad tiene con el entorno en que se ubica. Entendemos que, desde una perspectiva geográfica, el patrón espacial de uso del territorio se muestra como un factor clave en la generación del riesgo (Perles et al., 2006); la posición errónea de una determinada actividad humana puede generar el riesgo tanto por la activación artificial del peligro en las áreas causantes, como por la exposición de población, bienes y/o servicios territoriales vulnerables a la acción del peligro natural. Se trata de establecer el límite entre cuando un elemento o proceso del territorio pasa de ser un recurso a ser un peligro, límite que es subjetivo y

6 Patrón territorial: Distribución en el espacio de los usos humanos del territorio. (Población, bienes y servicios). (Zoido, 1998). 
dependiente de cada sociedad y momento temporal (Perles, 1999, a, b, c, d). Desde nuestra perspectiva, ordenar el patrón de usos del territorio de forma armónica con el patrón de peligrosidad es la vía de adaptación al riesgo ${ }^{7}$ más directa.

Por este motivo, consideramos fundamental enfatizar la importancia del patrón de distribución de los factores de riesgo físicos y humanos en el territorio, la dimensión espacial de los problemas de vulnerabilidad. Los factores de vulnerabilidad no son elementos deslocalizados ni abstractos; de su posición sobre el territorio depende en gran parte su nivel de fragilidad. El diseño de cartografías de vulnerabilidad expresivas, comparables, y aplicables adquiere en esta tendencia una particular importancia. Un mapa de vulnerabilidad es más aplicable si supera el nivel genérico y descriptivo para orientarse a la resolución de problemas específicos, y se concibe como una herramienta para aportar soluciones concretas en la gestión local del riesgo.

\section{II.2. Antecedentes metodológicos aplicados y dificultades asociadas}

La dispersión en el plano conceptual (Birkmann, 2014) se ha reflejado en una dificultad específica a la hora de dar el paso entre el concepto teórico de vulnerabilidad social y el plano aplicado, esto es, a la hora de diseñar metodologías concretas y extrapolables para la evaluación del concepto. Conmfort et al. (1999), Cutter et al. (2003) o Eaking y Luers (2006) señalan como la evaluación de la vulnerabilidad social presenta carencias en dos aspectos fundamentalmente: la dispersión de las estrategias metodológicas y la escasez de propuestas de indicadores que permitan el tránsito desde el plano teórico al aplicado.

El índice de vulnerabilidad aplicado a un espacio más genérico es el SoVI, (Cutter et al., 2003), con el que se obtuvo una cartografía de vulnerabilidad del territorio completo de EEUU. El SoVI se fundamenta en indicadores vulnerabilidad material frente al peligro, y de vulnerabilidad social y económica frente a la pérdida. En nuestra opinión, no diferenciar ambos conceptos, produce en este y otros índices de concepción similar un problema grave de interpretación, al obtener valores altos de vulnerabilidad tanto espacios muy poco desarrollados, con indicadores socio-económicos de alta vulnerabilidad, como otros lugares muy desarrollados y con alto nivel de vida que, al per der bienes y servicios cuantiosos, posen valores del índice elevados. Problemas similares de indefinición se observan en otras propuestas de índices y cartografías de vulnerabilidad, en unos casos por la mezcla en sus componentes de indicadores de muy distinta naturaleza, y en otros por el carácter global de la escala de aplicación del índice, con resultados muy genéricos y laxos, referidos a la vulnerabilidad social en abstracto, y no tanto a la vulnerabilidad frente al riesgo. Este es el caso del Índice de Vulnerabilidad Social en los Países de la OCDE aportado por Álvarez (2006) muy centrado en variables exclusivamente sociales de pobreza, ingresos, consumo, investigación y desarrollo; proporciona una visión genérica de la vulnerabilidad muy próxima a un indicador de desarrollo, pero deficiente a la hora de abordar problemas más concretos de vulnerabilidad frente a determinados peligros. Con (2009), construye un Índice de Vulnerabilidad Social (IVS) a partir de parámetros de vulnerabilidad física o material de la vivienda, junto a

7 Adaptación al riesgo: cualquier acción tomada por el individuo o colectividad con la intención de reducir el potencial de daños y, por tanto, los daños futuros (White, 1974). 
indicadores de condiciones sociales de la población, como son el hacinamiento del hogar, y la carga de dependencia sobre los perceptores de ingresos. Bollin y Hidajat (2006), otorgan a la vulnerabilidad un tratamiento diferenciado y un papel destacado al formular su índice de riesgo. Dwyer et al. (2004) realizan un esfuerzo de estructuración del concepto y proponen cuatro planos de la vulnerabilidad social: vulnerabilidad individual de las residencias, vulnerabilidad de la comunidad, vulnerabilidad regional/geográfica, vulnerabilidad administrativa/ institucional. En esta línea de identificación de matices en el concepto de vulnerabilidad, Schneiderbauer (2006) distingue dos tipos de vulnerabilidad: vulnerabilidad independiente y vulnerabilidad dependiente del peligro. Birkmann (2014), por su parte, identifica la vulnerabilidad con los conceptos de resiliencia, compuesto este a su vez por la capacidad de lucha y de adaptación de la sociedad frente al riesgo.

Las evaluaciones aplicadas de la vulnerabilidad no son muy abundantes en el ámbito europeo (Penning-Roswell, 2000; Wilson, 2002) aunque se asiste a un desarrollo progresivo de la temática en la actualidad. Autores como Paquier (2006) proponen valorar la exposición y la vulnerabilidad mediante el análisis comparado de la situación con medidas de mitigación o sin ellas. Otras aportaciones en la misma línea son propuesta a través de la Comisión Europea en su guía "Risk assessment and mapping guidelines for management (European Comission, 2010), en ella se establece un avance hacia el enfoque multi-riesgo y de múltiples peligros. Desde el punto de vista de la vulnerabilidad se establecen cuatro aspectos a tener en cuenta, exposición, factores de vulnerabilidad, evaluación de posibles impactos y capacidad de auto-protección. A nivel español existen algunas aportaciones como las realizada por Díaz-Herrero, (2002), en donde se establece la vulnerabilidad como componente geográficos del riesgo y se cataloga diferentes aspecto de la vulnerabilidad como son la sensibilidad, susceptibilidad o la política de protección de los receptores de la misma. En el marco andaluz, pueden citarse las cartografías editadas por Pita et al (1999), y los trabajos de Perles et al. (1999, a, b, c, d) y Perles, Vías y Andreo (2008) y Perles (2010) que conceptúan la noción de vulnerabilidad y reflexionan sobre el papel de la vulnerabilidad como hecho territorial.

En lo que se refiere al tratamiento de la vulnerabilidad social concretamente frente al riesgo de inundación, pueden destacarse las aportaciones realizadas por Hausmann (1999), en donde se concretan diferente acciones de lucha, o de autores como Messner y Meyer (2005) que se apoyan en indicadores de tipo social, económico o ecológico. Barroca, et al., (2006) plantean un modelo dinámico que facilita al usuario la selección de uno u otro indicador en función del contexto territorial. Gao y otros (2007) aplican en China métodos complejos multi-variables para manejar información de base muy compleja. Entre los métodos de difusión oficial más específicos se cuenta el propuesto por la UNESCO-IHE a través del Institute for Water Education. El F.V.I., (Fluvial Vulnerability Index) se fundamenta en los conceptos de exposición, susceptibilidad y resiliencia. Los indicadores del índice abordan las componentes social, económica, ambiental y física o territorial de la vulnerabilidad, aunque, por su propia concepción generalista, resulta poco preciso. Aplicaciones recientes en el ámbito de la cartografía de vulnerabilidad frente al riesgo de inundación pueden encontrarse en trabajos como el de Bescos y Camarasa (2004), Camarasa et al. (2008); Ruiz (2011); Garrote et al. (2016); Paucar (2016); Castillo (2016); o Aroca-Jiménez et al. (2016).

En lo que se refiere al tratamiento de la vulnerabilidad frente a la inundación en documentos normativos y de planeamiento, las principales aportaciones se han realizado a nivel 
autonómico. En el contexto de la comunidad autónoma de Andalucía, el Plan de Prevención de Avenidas e Inundaciones en los Cauces Urbanos Andaluces (2002), supuso un avance en lo que respecta a la utilización de medidas preventivas de control de la exposición y reducción de la vulnerabilidad en las zonas críticas. Otros ejemplos señeros de planeamiento integral del riesgo de inundación que conceden un cierto protagonismo al papel de la vulnerabilidad son, entre otros el PATRICOVA (2003) de la Comunidad Valenciana, el INUNCAT de Cataluña (2006), las directrices para el estudio de la inundabilidad expuestas en el Plan de Ordenación Territorial del Litoral de la Región de Murcia (2007), o el PRICAM de CastillaLa Mancha.

En el momento actual, a partir de la publicación del RD 903/2010 se incluye de forma específica la evaluación y cartografía de la vulnerabilidad frente a la inundación como paso para la elaboración de la Evaluación Preliminar del Riesgo de Inundación (EPRI) y de los Planes de Gestión del Riesgo de Inundación (PGRI), instrumentos previstos por la Directiva Europea de Inundaciones (2007/60/CE). Los requerimientos de la normativa en materia de vulnerabilidad, no obstante, son muy laxos y poco exigentes.

Un examen a los documentos aportados en estas fases de evaluación del riesgo muestra como la mayor parte de la cartografía de riesgo de inundación aplicada destinada al planeamiento territorial o a la gestión del problema en las respectivas Demarcaciones Hidrográficas se basan en procedimientos simplistas y en ocasiones, erróneos. Para evaluar la vulnerabilidad se aportan valores cuantitativos de exposición de la población, expresado en términos de densidad de habitantes, y de exposición de los bienes (a través de algún indicador del valor económico de las pérdidas potenciales). La vulnerabilidad, entendida en este contexto como el tanto por uno de la pérdida esperable, se calcula en función del grado de peligrosidad que tiene la zona en la que el bien o servicio a evaluar se sitúa (se entiende por tanto que un bien es más vulnerable si está situado en una zona más peligrosa). Al realizar la evaluación global del riesgo, se superponen los mapas de peligrosidad y vulnerabilidad así concebidos, por lo que la cartografía resultante se construye a partir de valores redundantes de peligrosidad.

El análisis crítico de las cartografías de vulnerabilidad frente a la inundación en distintos ámbitos, permite detectar como principales retos a resolver las cuestiones que se especifican en el siguiente apartado.

\section{II.3. Bases conceptuales de la propuesta metodológica}

\section{II.3.1. Principales retos y aspectos a resolver en el ámbito de las cartografías de vulnerabilidad frente a la inundación}

A partir del análisis de aportaciones teóricas y exigencias normativas en materia de inundación, se concluye que los principales problemas a resolver para obtener cartografías de vulnerabilidad útiles para la gestión del riesgo pueden resumirse como sigue:

- conceptuación imprecisa y cartografía de interpretación confusa: se observa un elevado grado de confusión conceptual que conduce a la elaboración de cartografías con indicadores de significado dispar, y, en consecuencia, de difícil interpretación. Los indicadores más habituales utilizados en la cartografía de vulnerabilidad, y así propuestos en la propia Directiva 
europea 60/2007, se aglutinan en torno a la idea de vulnerabilidad como equivalente al valor potencial de la pérdida. Es común determinar la vulnerabilidad de un territorio en razón del valor económico de la pérdida potencial de los usos del suelo instalados en él (Camarasa, 2008), lo que se traduce en cartografías que señalan como más vulnerables los espacios del territorio con usos o actividades más caras, pero no por ello más frágiles. Otras propuestas como la recogida en INSPIRE ${ }^{8}$ define la vulnerabilidad como tanto por uno de pérdida esperable sobre un determinado bien. Las cartografías que se fundamentan en esta definición calculan la pérdida esperable en razón de la posición del bien en cuestión en zonas de mayor o menor peligrosidad de la lámina de agua, por lo que, en consecuencia, la cartografía de vulnerabilidad obtenida reitera la distribución espacial de la peligrosidad, y considerara de forma muy indirecta la mayor o menor capacidad intrínseca de los elementos expuestos de resistir el envite de la peligrosidad. Por otra parte, la cartografía generada mediante este procedimiento no informa sobre las causas que generan la vulnerabilidad, y unifica en un mismo grado problemas de vulnerabilidad de solución muy diversa.

Es frecuente, de igual modo, utilizar en las cartografías de vulnerabilidad indicadores socio-económicos generales procedentes del ámbito de la sociología. Este tipo de indicadores se utilizan en el entendido de que una situación socio-económica de partida desfavorable (por ejemplo, nivel de paro) agrava el significado que la pérdida pueda tener en la economía familiar, y dificulta las posibilidades de recuperación. Sin embargo son muchos los malentendidos que se producen cuando este tipo de indicadores se aplican sin un criterio de coherencia espacial riguroso, ya que, si se sigue con el ejemplo empleado (nivel de paro), no existe necesariamente una correspondencia espacial en el territorio entre el elemento afectado por el peligro (por ejemplo, una determinada industria), y la ubicación espacial del propietario o los trabajadores vinculados a ella, cuya desfavorable situación socioeconómica pudiera agravar el significado de la pérdida. El elemento vulnerable frente al peligro y la población vulnerable frente a la pérdida de dicho elemento, no siempre coinciden en el espacio.

- Dispersión metodológica. Laxitud de criterios a la hora de seleccionar los indicadores de vulnerabilidad frente a la inundación: las normativas que instan a la elaboración de cartografías de vulnerabilidad no proponen criterios reglados, ni indicadores específicos. El resultado de este problema es la elaboración de cartografías con criterios dispares y, por tanto, no comparables. Existen también un alto grado de dispersión a la hora de establecer índices globales y criterios de ponderación; la unificación de los distintos mapas parciales de vulnerabilidad hacia un resultado unitario se realiza siguiendo criterios diferentes en cada caso.

- Incoherencia espacial. Es común el uso de indicadores de vulnerabilidad de expresión espacial sintética (límites artificiales), que no se corresponden con la distribución espacial de la peligrosidad de inundación, de naturaleza espacial analítica (límites de la lámina de agua). Este hecho provoca, en muchos casos, la no correspondencia espacial real entre el elemento expuesto que se está tratando y la lámina de inundación, lo que falsea e incluso invalida el propósito del mapa (por ejemplo datos de población expresados a nivel municipal o distrito censal que se atribuyen al conjunto de la unidad artificial, cuando el espacio inundable afecta sólo a una parte del municipio).

8 Infrastructure for Spatial Information in Europe. 


\section{II.3.2. Aportaciones de la propuesta. Aclaraciones respecto a distintos aspectos implicados en la vul- nerabilidad}

La noción de vulnerabilidad en la que se fundamenta la cartografía elaborada en el artí-

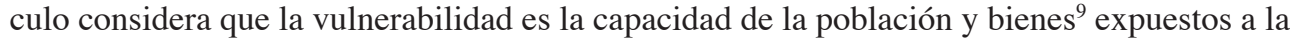
acción de un peligro de resistir el impacto del mismo y recuperarse del daño. La cartografía de vulnerabilidad engloba el concepto de magnitud de elementos expuestos (exposición), y el de vulnerabilidad en sentido estricto de esos elementos. La vulnerabilidad depende de factores biofísicos, conductuales y territoriales (Vías et al., 2003; Perles et al., 2008; Perles, 2010). Desde esta idea inicial, es necesario aclarar algunos aspectos implicados.

Vulnerabilidad ifrente a qué? La vulnerabilidad del territorio frente a la inundación se define por el conjunto de características del mismo que le capacita para resistir en mejor medida el impacto de la inundación. Es imprescindible diferenciar si el elemento expuesto es vulnerable frente al peligro en sí, esto es, frente a la agresión de la crecida, o si es vulnerable frente a la pérdida, esto es, una vez se haya producido el impacto negativo, lo que significará que la capacidad de recuperación del elemento expuesto será baja. Mezclar indicadores de vulnerabilidad frente al peligro y frente a la pérdida genera cartografías de interpretación confusa, ya que estos conceptos no tienen por qué ser coherentes, ni directamente proporcionales, y además requieren soluciones de naturaleza muy distinta en el ámbito de la gestión del riesgo. Las edificaciones de construcción precaria asociada a viviendas de población marginal pueden ser un ejemplo ilustrativo de la necesidad de matizar frente a qué se es vulnerable. El elemento expuesto es muy frágil frente a la crecida e inundación, y, sin embargo, el coste de su pérdida escaso, pero a la vez el significado de su pérdida para el individuo o grupo social, muy importante. Estas incoherencias a la hora de diseñar instrumentos aplicados para la evaluación de la vulnerabilidad son reflejo de problemas subyacentes de conceptuación imprecisa sobre la materia.

En el caso de la cartografía de vulnerabilidad frente al peligro, en nuestra propuesta cartográfica se ha considerado la peligrosidad implícita en la crecida, pero también los de otros peligros asociados a la inundación (Perles, 2010), como el de erosión, movimientos gravitacionales, o contaminación, entre otros, que en ocasiones generan problemas de vulnerabilidad específicos en los elementos expuestos.

Vulnerabilidad ¿para qué? La propuesta de cartografía de vulnerabilidad que se expone se fundamenta en la idea de "construcción de la seguridad" propuesta por Clarck (1999), y en el espíritu del documento "Guidance for Reporting under the Floods Directive", publicado por la Comisión Europea (2013). Se propone un enfoque que zonifique el espacio de riesgo y su vulnerabilidad en razón de la búsqueda de soluciones, esto es, que se oriente hacia la identificación de unidades espaciales y elementos del territorio útiles para la gestión del riesgo (Perles 2006, 2007, 2010). Este mismo enfoque subyace también en el concepto de riesgo territorial propuesto por Veyret, Beucher y Bonnard (2005).

9 El concepto de bien en este contexto incluye todo aquello que es valioso para el ser humano y la sociedad, sea su valor de naturaleza económica, patrimonial, medio-ambiental, sentimental, etc. Están incluidos en el concepto, además de bienes de naturaleza material, junto a las actividades productivas y los servicios territoriales. 
La estructura de la metodología y de la cartografía consecuente se fundamenta en un esquema de identificación preciso de problemas de vulnerabilidad que se han organizado en razón del tipo de solución a aplicar para su mitigación. (medidas de mitigación en cada fase). Se ha cuidado no mezclar problemas con distintas soluciones. Se pretende así aportar un instrumento cartográfico de apoyo para la aplicación de cada medida de gestión específica.

Es necesario precisar que la propuesta se concibe como una herramienta para la resolución de problemas de vulnerabilidad frente a la inundación, pero se restringe hacia la mitigación de problemas que puedan resolverse desde el ámbito de la gestión del riesgo. A fin de acotar el problema a resolver, y aportar documentos útiles para su solución, no se ha insistido en mapas relativos a cuestiones genéricas de vulnerabilidad de la población frente a cualquier impacto, sino en cómo las causas subyacentes de índole contextual, las denominadas "external forces" por Turner et al. (2003) o contexto de riesgo por Calvo García-Tornell (2001), inciden y generan de forma específica la vulnerabilidad frente a la inundación.

Vulnerabilidad ¿responsabilidad de quién? Es necesario precisar como la vulnerabilidad frente al riesgo puede tener una dimensión dentro de la esfera individual o en la esfera colectiva. La titularidad pública o privada de los elementos expuestos hace que el grado de responsabilidad por parte de la administración pública sobre la resolución de los impactos sea variable según el caso.

En el caso de la metodología que nos ocupa, al concebir la cartografía de vulnerabilidad como herramienta de apoyo para la aplicación de medidas de mitigación, se ha procurado proponer documentos que permitan discernir la responsabilidad pública o individual en la resolución de los problemas.

Vulnerabilidad ¿dónde? Dado que la peligrosidad de inundación posee una delimitación espacial analítica muy precisa (lámina de inundación), a la hora de identificar los elementos expuestos y su vulnerabilidad es necesario un especial esfuerzo de correspondencia entre el espacio de peligro y las unidades espaciales en la que la información estadística temática viene expresada. En la propuesta se aportan estrategias de adaptación de las fuentes con adscripción espacial sintética para conocer su vinculación real con las distintas zonas de peligrosidad. Variables como la densidad de población expuesta, han sido adaptadas en este sentido.

¿Vulnerabilidad comparable? En aras de su aplicabilidad, la metodología propuesta se fundamenta en indicadores y fuentes disponibles en repositorios de información accesibles, editados en su mayoría por servicios de la propia Administración, para posibilitar que el proceso de elaboración de los mapas sea equivalente en todas las cuencas y demarcaciones hidrográficas. Al objeto de conseguir una gradación de la vulnerabilidad interpretable en términos comparativos, al diseñar los intervalos de gravedad para los mapas de exposición y vulnerabilidad se ha partido de datos de referencia sobre el parámetro en cuestión en el conjunto de las áreas inundables de Andalucía. Mediante procedimientos estadísticos de medida de tendencia central y dispersión, para cada variable indicativa de vulnerabilidad o exposición se han calculado los valores medios, y, por ende, normales, en el territorio andaluz. Estos datos se han utilizado como referencia a la hora de definir los umbrales entre los intervalos alto, medio y bajo de vulnerabilidad. De esta forma los intervalos de gravedad no sólo resultan comparables entre sí en las distintas cuencas, sino que se corresponden de forma realista con la gradación de la gravedad de la variable en el territorio. El espacio utilizado como referencia para la estimación de valores medios es la superficie inundable de Andalucía, aunque el método de evaluación y los 
umbrales delimitados son extrapolables a cualquier otro territorio con un patrón territorial similar, ya que la casuística de circunstancias de vulnerabilidad analizadas en la muestra andaluza es muy extensa y variada (cuencas con perfil agrario, industrial o urbano, modelos de distribución del poblamiento y la población muy dispar, densidad de infraestructuras desigual, etc.).

\section{METODOLOGÍA DE ELABORACIÓN DEL CATÁLOGO CARTOGRÁFICO}

\section{III.1. Características generales de la metodología propuesta}

La metodología propuesta tiene como objetivo generar un conjunto de documentos cartográficos útiles para la resolución de los problemas de vulnerabilidad frente a la inundación que sirvan de herramienta de apoyo para la aplicación de las medidas de mitigación indicadas en los Planes de Gestión del Riesgo de Inundación, a aplicar a través de los Planes de Actuación de Ámbito Local.

El resultado del trabajo es, por tanto, una propuesta de catálogo cartográfico de vulnerabilidad cuyas características se exponen a continuación. El catálogo cartográfico incluye mapas de exposición y de vulnerabilidad, tanto de la población como de los bienes expuestos. La estructura del catálogo se organiza igualmente en razón de dos grandes conceptos: la vulnerabilidad frente al peligro de inundación, y la vulnerabilidad frente al impacto. La cartografía relativa a la vulnerabilidad frente al peligro permite identificar las zonas del territorio más susceptibles de recibir daños en razón de la fragilidad de la población o bienes que se ubican en ella. En el contexto de la gestión del riesgo, la cartografía de vulnerabilidad frente al peligro sirve para identificar las zonas más necesitadas de medidas preventivas pre-catástrofe, al objeto de evitar un porcentaje del daño sobre el elemento expuesto. Igualmente, esta cartografía es útil para orientar la fase de gestión de emergencias simultánea a la catástrofe. La fragilidad de las personas o bienes frente al peligro puede estar causada por debilidad bio-física, o conductual. En otros casos el elemento expuesto puede ser especialmente sensible si tiene un valor excepcional para la comunidad (valores patrimoniales, intangibles) y difícil posibilidad de reposición. De igual modo un elemento también puede ser considerado vulnerable si su función es básica o estratégica para la comunidad; el alto valor de la pérdida potencial de un bien, sin embargo, no lo hace más frágil frente al peligro. La cartografía de vulnerabilidad frente a la pérdida, definen la resiliencia, es decir identifica las zonas del territorio en que será más o menos fácil la normalización tras la catástrofe. La vuelta a la normalidad dependerá del valor económico de la pérdida en cada sector del territorio y sobre todo del significado relativo de la pérdida sobre el individuo y la comunidad, que a su vez está condicionado por la situación socio-económica de partida de la población afectada; por otra parte la capacidad de recuperación depende de la existencia y eficacia de sistemas de compensación y rehabilitación. La cartografía de pérdidas potenciales orientan sobre dónde los costes de reposición serán más elevados (información vinculada esencialmente al ámbito privado de los propietarios del bien afectado y a las aseguradoras). De mayor interés en el ámbito de la gestión pública del riesgo son los documentos que ponen en relación los costes de la pérdida con la situación económica de partida de los propietarios, ya que orientan al gestor del riesgo sobre las zonas que previsiblemente necesitarán un mayor apoyo público de políticas rehabilitadoras tras la catástrofe. 
Se propone un catálogo de mapas estructurado en función de los problemas concretos de vulnerabilidad a tratar. La secuencia de razonamiento utilizada da respuesta a las siguientes preguntas: ¿Cuál es el problema de vulnerabilidad?; ¿qué medidas de mitigación podrían aplicarse y se han previsto en los Planes de Gestión del Riesgo?; ¿qué cartografía es útil para aplicar dichas medidas de mitigación?

\section{III.2. Identificación de problemas de inundación relacionados con la vulnerabilidad}

Como se ha citado, cada uno de los mapas propuestos en el catálogo de cartografía de vulnerabilidad está pensado para abordar problemas específicos que se producen en torno al problema de la inundación. Para la identificación de problemas a abordar se ha partido de los procedimientos que se exponen a continuación:

1. Análisis de eventos de inundación anteriores e identificación de problemas específicos relacionados con la vulnerabilidad de los elementos expuestos. El análisis se ha fundamentado en datos de prensa, fuentes bibliográficas y entrevista a actores sociales afectados.

2. Observación y delimitación de espacios problemáticos por inadaptación entre el patrón de ocupación del territorio y la peligrosidad de inundación, al objeto de identificar un modelo descriptivo-explicativo de la producción de la vulnerabilidad en diferentes situaciones tipo (áreas rurales, urbanas, periurbanas y litorales).

3. Compilación de los problemas relacionados con la vulnerabilidad identificados en los Planes de Gestión del Riesgo de Inundación, y de las medidas de mitigación y actuaciones a aplicar previstas para la mejora de estos problemas. Se han diseñado documentos cartográficos que sirvan como herramienta en la aplicación de estas medidas. Se ha procurado, por ello, no mezclar en la cartografía información sobre problemas que tengan soluciones distintas.

Los principales problemas identificados en las crisis de inundación analizadas han sido los siguientes:

Problemas relacionados con la vulnerabilidad frente al peligro:

1. Interrupción de servicios territoriales básicos

2. Aislamiento de la población

3. Dificultades de socorro y asistencia

4. Conductas arriesgadas o inseguras de la población

5. Afección de bienes o sectores del territorio especialmente sensibles

6. Afección de elementos del territorio por contaminación y otros riesgos asociados a la inundación

Problemas relacionados con la vulnerabilidad frente a la pérdida y resiliencia

7. Generación de grandes pérdidas

8. Dificultad de la población para la recuperación tras el impacto 
Dado que se trata de una propuesta cartográfica, se han considerado únicamente aquellos aspectos de la vulnerabilidad en los que la distribución espacial es significativa a la hora de mitigar el problema y dar prioridad a unos sectores del territorio sobre otros. No se han seleccionado indicadores de vulnerabilidad que, por tener una escasa variabilidad espacial a la escala de trabajo utilizada, se comporten como una constante en la cartografía y no aporten capacidad de discriminación al mapa.

Para posibilitar la aplicabilidad de la propuesta cartográfica por parte de organismos de la Administración Pública o por consultorías ambientales, sólo se seleccionado indicadores que puedan ser generados mediante fuentes editadas de fácil acceso y de información general y equivalente, en este caso, para el conjunto del territorio andaluz. Se han descartado, por tanto, indicadores válidos pero que por su dificultad de obtención tienen interés en el ámbito de la investigación, pero no son útiles para la gestión aplicada del riesgo. A continuación se recopilan las principales fuentes utilizadas para la elaboración del catálogo cartográfico:

- DERA: Datos Espaciales de Referencia de Andalucía. Escala 1:100.000. Año: 2015.

- SIOSE: Sistema de Información sobre Ocupación del Suelo del España. Escala 1:10:000. Año 2007

- CartoCiudad: Red viaria continúa de España. Diversas escalas de trabajo. Año: 2015.

- Catastro: Dirección General de Catastro Virtual. Escala variable. Año: 2015

- Google Earth. Escala variable. Año: 2015

- Planes Hidrológicos. Escala variables. Años: según Organismo de cuenca.

- Atlas de Vulnerabilidad Urbana de España. Escala infra municipal. Año: 2015.

\section{CATÁLOGO CARTOGRÁFICO DE VULNERABILIDAD FRENTE A LA INUNDACIÓN}

\section{IV.1. Bloque E: mapas relativos a la Exposición}

\section{IV.1.1. Mapas relativos a la exposición de la población (Ep):}

- Mapa Ep1: Volumen de población afectable por la inundación (en el área inundable y fuera del área inundable)

- Mapa Ep2: Densidad de población afectable por la inundación (en el área inundable y fuera del área inundable)

- Mapa Ep3: Puntos de concentración de la población expuesta en el área inundable

La exposición de la población a la inundación es posiblemente la variable más básico en las cartografías de vulnerabilidad, aunque no siempre es tratada de una forma correcta. Una aportación de la metodología en este punto es el tratamiento particularizado que se le ha dado a la variable. Por una parte se ha identificado como población expuesta no sólo la residente dentro del espacio inundable, sino también la situada fuera de este área pero susceptible de quedar aislada, y por tanto afectada por la inundación. Por otra parte, a la hora de estimar los valores de exposición de la población dentro del área inundable, se ha ponderado a la baja el volumen de población expuesta en las zonas con viviendas plurifamiliares en altura (menor grado de exposición que los residentes en viviendas en planta baja), generando así un valor de población 
expuesta modificado, más ajustado a la probabilidad real de afectación. El primer mapa (Mapa Ep 1) aporta un valor de exposición de la población en términos absolutos (volumen de población), y en el segundo (Mapa Ep 2) se utiliza un indicador de densidad de población expuesta (calculada a partir de los mencionados valores de población expuesta modificada); para dimensionar el significado relativo de los valores de volumen y densidad de población expuesta, en relación a otras cuencas y zonas de estudio, los intervalos de representación del mapa se han delimitado utilizando como referencia los valores de volumen y densidad medios en el conjunto de otras áreas inundables (en este caso, el universo de cálculo han sido el conjunto de las zonas inundables de Andalucía). Mediante este procedimiento se ha conseguido que el mapa aporte información en términos absolutos, y, a su vez, umbrales de referencia para dimensionar la magnitud de la exposición en términos comparativos. Como complemento a los valores de volumen y densidad de población expuesta, el catálogo incluye el Mapa Ep3, en el que se indican las zonas del territorio en las que el uso del suelo propicia la concentración eventual de la población, por lo que los valores de exposición estándar pueden verse multiplicados.

\section{IV.1.2. Mapas relativos a la exposición de bienes (Eb)}

- Mapa Eb4: Superficie cultivada susceptible de ser inundada

- Mapa Eb5: Superficie de uso ganadero susceptible de ser inundada

- Mapa Eb6: Superficie de uso industrial susceptible de ser inundada

- Mapa Eb7: Superficie residencial o de servicios susceptibles de ser inundada

- Mapa Eb8: Superficies de infraestructuras y equipamientos susceptibles de ser afectadas

- Mapa Eb9: Superficie de zonas protegidas y elementos patrimoniales susceptible de ser inundadas

Como puede observarse, los mapas relativos a la exposición se fundamentan en los elementos del territorio representativos de los principales sectores productivos, de la estructura de servicios territoriales básicos (infraestructuras y equipamientos), y de las zonas protegidas como valor patrimonial natural o cultural.

\section{IV.2. Bloque V: mapas relativos a la vulnerabilidad}

IV.2.1. Mapas orientados a la resolución de problemas relacionados con la vulnerabilidad frente al peligro (Vpe):

Problema 1: Interrupción de servicios territoriales básicos

Mapa Vp1: Servicios territoriales básicos interrumpidos por la inundación gradados según el alcance espacial de las repercusiones.

Mapa Vp 1.1: Servicios de socorro y asistencia a la población afectables por inundación o aislamiento según su ámbito de acción (local/ regional/ internacional)

Mapa Vp 1.2: Equipamientos básicos afectados por inundación o aislamiento según su ámbito de acción (local/ regional/ internacional) 
Mapa Vp 1.3: Infraestructuras de transporte afectables por inundación o aislamiento según su ámbito de acción (local/ regional/ internacional)

Mapa Vp2: Puntos de interrupción del tráfico en carreteras por inundación gradados según la magnitud de sus repercusiones (volumen de tráfico interrumpido y de población afectada)

Mapa Vp 2..1: Puntos de interrupción del tráfico en carreteras por inundación gradados según la importancia del tráfico que interrumpen (IMD)

Mapa Vp 2..3: Puntos de corte en las infraestructuras viarias por inundación gradados según el volumen de población que afecta.

\section{Mapa Vp 3: Otras infraestructuras no viarias afectables por inundación o aislamiento}

El primer grupo de mapas relativos a la vulnerabilidad (Vp1) están diseñados para abordar el problema de la interrupción de los servicios territoriales básicos durante la inundación. La interrupción de los servicios puede estar causada por inundación directa de las instalaciones que prestan el servicio, o por problemas de interrupción en el acceso a las mismas. Las consecuencias se han gradado en razón del carácter local, regional o internacional del servicio prestado.

Se han identificado como problemas específicos la interrupción de servicios de socorro durante la crisis (prestados por agentes como bomberos, policía, UME, hospitales y centros de salud). De igual modo se identifica en un segundo mapa los elementos del territorio cuya afectación puede generar una mayor disfunción en servicios funcionales básicos tales como sanitarios, educativos, administrativos, y comerciales expendedores de productos básicos. En un tercer mapa se aporta información sobre la posible afección del sistema general de transporte (carreteras, ferrocarriles, metros o tranvías, aeropuertos y puertos).

Los mapas siguientes (Vp2) aportan información sobre cuáles son los tramos de la carreteras afectadas por la inundación más vulnerables, en razón de la mayor o menor importancia de las consecuencias que genere el corte de tráfico. En el Mapa Vpe 2.1 se localizan como más vulnerables aquellos puntos de las infraestructuras viarias cuya inundación interrumpe una intensidad de tráfico mayor. La intensidad se ha medido según la IMD de vehículos y un coeficiente de intensificación del tráfico en aquellos puntos inundados de la carretera que afecten a trayectos de máxima necesidad de uso durante la crisis (conexiones entre equipamientos y funciones estratégicas del territorio en momentos de crisis). El Mapa Vpe 2.2 indica qué puntos de corte de las infraestructuras afecta a un mayor volumen de población.

Por último el mapa Vp 3 muestra los posibles puntos de afectación a las infraestructuras energéticas, de saneamiento, y de abastecimiento hídrico.

Problema 2: Aislamiento de la población

Mapa Vp 4: Volumen de población con posibilidad de quedar aislada situada dentro y fuera del área inundable, gradadas según su nivel de aislamiento

Mapa Vp 4.1 Población con posibilidad de quedar aislada dentro del área inundable según su grado de aislamiento 
Mapa Vp 4.2: Población fuera del área inundable susceptible de quedar aislada por cortes en las carreteras de acceso, según su grado de aislamiento

Mapa Vp 4.3: Principales centros de trabajo que supongan concentraciones de población susceptibles de quedar aislados (industrial, servicios) según su grado de aislamiento

El problema del aislamiento de la población incluye una doble casuística: la población que queda rodeada por la lámina de inundación y la que, fuera del área inundable queda aislada por cortes en las carreteras de acceso a la zona residencial. El mapa Vp 4 recoge información sobre los espacios del territorio con más carga de población susceptible de quedar aislada, y sobre su grado de aislamiento. En todos los casos, la estimación del volumen de población se ha realizado mediante un procedimiento preciso de ajuste entre los valores de población del distrito censal, los datos de población expresados en cuadriculas raster provenientes del DERA y los metros cuadrados habitados dentro de cada cuadrícula o sección censal (considerando el número de plantas de los edificios), al objeto de calcular la densidad media de población en el espacio habitado, y, en última instancia, el volumen de población total correspondiente a la zona residencial que queda aislada por el corte de tráfico. El mapa Vp 4.3 complementa la información sobre el problema de aislamiento al identificar la ubicación de los principales centros de trabajo susceptibles de quedar aislados que supongan concentraciones extraordinarias de población.

Problema 3: Dificultades de socorro y asistencia

Mapa Vp 5: Sectores del territorio con especiales necesidades potenciales de socorro (rescate, asistencia, vigilancia) gradados según la accesibilidad a estos servicios.

Mapa Vp 5.1.Sectores del territorio con especiales necesidades de rescate (población dependiente, edificios sin refugio)

Mapa Vp 5.2 Sectores del territorio con especiales necesidades de asistencia (bombeo de agua, desbloqueo de drenaje, retirada de materiales) (sótanos, viales con dificultad de drenaje)

Mapa Vp 5.3 Sectores del territorio con especiales necesidades de vigilancia durante la crisis (desorden, saqueos)

Mapa Vp 5.4: Accesibilidad de los servicios de socorro y asistencia a los sectores del territorio con mayores necesidades potenciales.

El mapa Vp 5 y los asociados que lo complementan abordan el problema de las necesidades de socorro de la población durante la crisis de inundación. Se ha considerado tanto la población afectada por la propia lámina de agua como la que se sitúa fuera del espacio inundable pero afectable por aislamiento. Se han identificado en mapas separados las distintas necesidades de socorro; por un lado en el mapa Vp5.1 se consideran las necesidades de rescate y/o asistencia médica (fundamentalmente población dependiente por motivos de edad o minusvalía agrupados en centros o instituciones y habitantes de viviendas inundables sin posibilidad de refugio en un segundo piso o terraza, y /o con disposición de la edificación transversal al flujo); por otra parte, en el mapa Vp 5.2, se identifican las zonas con necesidades de labores de intervención sobre la vivienda (bombeo de plantas bajo rasante), o sobre otros elementos del territorio 
(desbloqueo de viales con dificultades de drenaje). Se han identificado en este sentido aquellos puntos del trazado viario que por su configuración morfométrica y su disposición frente al flujo propician el bloqueo o retención del caudal. Por último, en el mapa Vp 5.3 se cartografían los sectores del territorio con más probabilidad de sufrir saqueos, y necesidades específicas de vigilancia. Se ha considerado que las zonas más susceptibles de saqueo son aquellas en las que se almacenan bienes muebles transportables (centros comerciales, supermercados, almacenes, etc.), y a la vez se sitúan en un entorno con problemas de delincuencia

En todos los casos se ha elevado el nivel de vulnerabilidad intrínseca del elemento territorial en cuestión si este se encuentra localizado en la Zona de Peligrosidad Alta (Diez Herrero, 2008). El conjunto de mapas alusivos a las necesidades de socorro y asistencia se ha gradado según la accesibilidad de los servicios de socorro y asistencia respecto a los sectores del territorio potencialmente más necesitados. El mapa de accesibilidad se fundamenta en isócronas calculadas desde los puntos de prestación del servicio, hacia la población que potencialmente lo requiere. Se identifican así las zonas del territorio con población necesitada de asistencia que quedan más desistidas (atención más lenta), y que por tanto son más vulnerables.

Problema 4: Conductas arriesgadas o inseguras de la población. Necesidades de información.

\section{Mapa Vp 6: Colectivos de población con especiales necesidades de información sobre comportamiento frente a la catástrofe \\ 5. Mapa Vp 7: Trayectos del viario con alta vulnerabilidad (alta concentración de tránsito) durante los momentos de máxima alerta y peligrosidad.}

Este conjunto de mapas está orientado a tratar problemas de aumento de la vulnerabilidad por pautas conductuales arriesgadas por parte de la población. En el primer documento (Mapa Vp 6), se señalan como más vulnerable los colectivos de población de los cuales pueda presuponerse una cierta dificultad para la percepción ajustada de los mensajes de alerta y recomendaciones de comportamiento ante la catástrofe, y/o un grado elevado de desconocimiento del funcionamiento de una inundación en un contexto mediterráneo. Los colectivos se han señalado en razón de la edad y necesidad de comportamiento colectivo coordinado (colegios de educación primaria, residencias de ancianos), y de las dificultades de comprensión del idioma (turistas en hoteles, y centros de inmigrantes)

El segundo documento de este apartado, el mapa Vp 7 recoge un problema de conducta arriesgada común en los momentos de crisis, como es la alta concentración de población en determinadas rutas del viario generando así atascos, bloqueos y situaciones de alta exposición y vulnerabilidad, especialmente si estas rutas coinciden con puntos de alta peligrosidad de inundación (ZPA). Las rutas más proclives a la concentración han sido trazadas alrededor de los puntos del territorio que pueden actuar como reclamo (recogida de población infantil u otra población dependiente de colegios y guarderías), y también de las zonas de concentración de la población por motivos funcionales que en momentos de alerta actúan como puntos de salida masiva y simultánea (salida de parkings, entorno de centros comerciales, y de polígonos industriales). Desde estos puntos se ha trazado el trayecto hacia las vías de mayor flujo de conectividad en el entorno. 
Problema 5: Afección de bienes o sectores del territorio especialmente sensibles

- Mapa Vp 8: Bienes de especial valor para la comunidad (patrimonial, natural, paisajístico, identitario, etc.) expuestos a la inundación, según la importancia de su valor

- Mapa Vp 9: Bienes de especial fragilidad material frente a la inundación (viviendas frágiles, automóviles y otros bienes)

El siguiente grupo de documentos del catálogo cartográfico se centra en la identificación de bienes especialmente vulnerables frente al impacto de la lámina de agua. El bien puede ser excepcionalmente vulnerable por causa de su excepcionalidad, su especial significado para la comunidad, y/o su dificultad de reposición (es el caso de los valores patrimoniales culturales o naturales, o de cualquier otro bien con significado identitario); este concepto se recoge en el mapa Vp 8. Por otra parte, el mapa Vp 9 recoge otra casuística de vulnerabilidad de los bienes. En él se identifican bienes que por sus características materiales o bio-físicas especialmente frágiles son poco resistentes al contacto con la lámina de agua. Este es el caso, por ejemplo de las viviendas frágiles por características constructivas (presencia de sótanos, disposición transversal al flujo, mal estado de conservación, indicadores de construcción precaria), de los automóviles (se han cartografiado sólo los concentrados en parkings), y de algunos usos del suelo como las zonas de huerta y de ganadería estabulada.

Problema 6: Afección de elementos del territorio por contaminación y otros riesgos asociados a la inundación

- Mapa Vp 10: Usos del suelo especialmente sensibles frente a aguas de inundación contaminadas, ofrente a las consecuencias de otros peligros asociados a la inundación.

El mapa Vp 10 identifica la especial vulnerabilidad frente a la inundación con aguas contaminadas de determinados usos y actividades, como las captaciones de agua destinadas a consumo humano, las masas de agua e instalaciones dedicadas a uso recreativo, y los espacios naturales protegidos

IV.2.2. Mapas orientados a la resolución de problemas relacionados con la vulnerabilidad frente a la pérdida y capacidad de recuperación (Vr):

Problema 7: Elevado coste de reposición de la pérdida de bienes

Mapa Vr 11: Potencial de pérdida económica de distintos usos del suelo (agrario, edificaciones, vehículos)

Mapa Vr 11.1: Potencial de pérdida económica de la terrenos agrarios

Mapa Vr 11.2: Potencial de pérdida económica de las edificaciones afectables

Mapa Vr 11.3: Potencial de pérdida económica de vehículos

Para la estimación del potencial de pérdida, el primer paso es identificar el valor económico de partida de cada uno de los bienes. Para este cometido, y en aras de la aplicabilidad de la metodología, se ha recurrido a fuentes de información de fácil acceso. El valor de los usos agrarios expuestos (Mapa Vp11. 1) se ha estimado a partir de los datos sobre usos agrarios procedente 
del catastro de rústica, valorados económicamente a partir de los criterios para distintos cultivos recogidos en la Agencia Tributaria de Andalucía (Consejería de Hacienda y Administración Pública). En el caso de las edificaciones afectables (Mapa Vp 11.2), cartografiadas a partir del catastro de urbana y rústica, el valor de la edificación ha sido asignado en razón de su extensión, de algunos indicadores de marginalidad, y de los costes medios de construcción según tipología aportados por distintos colegios de arquitectos. El valor de los automóviles expuestos a la inundación ha sido calculado en razón de costes medios de mercado, y el volumen de automóviles expuesto se ha deducido mediante la identificación de zonas de parking en el trazado viario.

Una vez evaluado el valor de los bienes expuestos, se ha calculado el porcentaje de pérdida esperable. Para evaluar en qué medida el bien se verá afectado y producirá pérdida se han considerado, en primer lugar, aspectos relacionados con la vulnerabilidad intrínseca del bien expuesto frente al peligro. Se han estimado porcentajes de pérdida mayores en los cultivos más sensibles frente a la inundación, y a las edificaciones con peor estado de conservación y mayor nivel de precariedad en la construcción. Por último el porcentaje de pérdida estimado se ha ponderado en razón de la posición del bien en cuestión (parcela, edificación, o automóvil) sobre una zona de mayor o menor intensidad de la peligrosidad.

Problema 8: Dificultades específicas para la recuperación tras el impacto

\section{Mapa Vr 12: Indicadores de nivel económico de la población residente en el área inundable \\ Mapa Vr 13: Capacidad de resiliencia económica de la población residente en las viviendas con mayor posibilidad de afectación}

El mapa Vr 12 se aproxima al estatus económico del entorno mediante distintos estimadores indirectos referidos a la situación laboral de la población y el valor de sus bienes (nivel de paro, indicadores de valor de la vivienda, nivel de delincuencia). Este mapa da una idea de referencia de la situación económica de partida de la población, y de su solvencia en la fase de recuperación y normalización.

El mapa Vr 13 da una idea más precisa de la resiliencia de las viviendas del espacio inundable, al relacionar los casos de vivienda con mayor posibilidad de sufrir daños (las identificadas como más frágiles frente al peligro, que a su vez se sitúan en zonas de mayor peligrosidad), con un indicador sintético del estatus económico de la población que reside en estas viviendas. Se identifican así como menos resilientes las viviendas con mayor posibilidad de sufrir daños (no con mayor potencial de pérdida económica), en las que residen población con una situación económica de partida desfavorable. Se entiende que en estos casos el significado de la pérdida en la economía familiar es muy importante, aunque el volumen de pérdida no sea muy cuantioso.

A continuación se ofrece una tabla resumen con las variables utilizadas para la elaboración del catálogo cartográfico, en la cual se han utilizado de manera genérica las siguientes variables:

- Lámina de inundación (periodo de retorno de 1000 años). Fuente: EHCB

- Infraestructuras viarias afectadas por calados superiores a 0.5 metros. Fuente: EHCB

Las variables específicas para la obtención de los distintos mapas del catálogo se especifican en la tabla $\mathrm{N}^{\mathrm{o}} 1$. 
Tabla 1

RESUMEN DE VARIABLES Y FUENTES EMPLEADAS EN EL DESARROLLO DEL CATÁLOGO CARTOGRÁFICO

\begin{tabular}{|c|c|c|c|c|c|}
\hline \multicolumn{2}{|c|}{ Bloque temático } & \multirow{2}{*}{\multicolumn{2}{|c|}{$\begin{array}{c}\text { Mapas } \\
\begin{array}{c}\text { Población expuesta afectada por inundación o } \\
\text { aislamiento }(\text { Ep1) }\end{array}\end{array}$}} & \multirow{2}{*}{\begin{tabular}{|l|}
\multicolumn{1}{|c|}{ Variables } \\
$N^{o}$ de habitantes afectados \\
por núcleo de población (por \\
inundación y/o aislamiento). \\
\end{tabular}} & \multirow{2}{*}{$\begin{array}{c}\text { Fuentes } \\
\text { DERA }\end{array}$} \\
\hline \multirow{9}{*}{ : } & \multirow{3}{*}{$\begin{array}{l}\text { Exposición de } \\
\text { la población. }\end{array}$} & & & & \\
\hline & & $\begin{array}{r}\text { Población e } \\
\text { aisl }\end{array}$ & $\begin{array}{l}\text { xpuesta afectada por inundación o } \\
\text { amiento (densidad).(Ep2) }\end{array}$ & $\begin{array}{l}\text { Densidad de población afectada } \\
\text { (por inundación o aislamiento). }\end{array}$ & DERA \\
\hline & & Puntos de ct & $\begin{array}{l}\text { excentración espacial de población } \\
\quad \text { expuesta (Ep3) }\end{array}$ & $\begin{array}{l}\text { Centros comerciales, colegios, } \\
\text { hospitales, aeropuertos, puertos, } \\
\text { estaciones de trenes, etc. afectados } \\
\text { en el área inundable }\end{array}$ & $D E R A$ \\
\hline & \multirow{6}{*}{$\begin{array}{l}\text { Exposición } \\
\text { de bienes y } \\
\text { servicios. }\end{array}$} & & Usos agrícolas. (Eb4) & $\begin{array}{l}N^{o} \text { de hectáreas cultivadas en la } \\
\text { zona inundables. }\end{array}$ & SIOSE \\
\hline & & & Usos ganaderos. (Eb5) & $\begin{array}{l}N^{o} \text { de hectáreas de usos ganaderos } \\
\text { en la zona inundable. }\end{array}$ & SIOSE \\
\hline & & & Isos industriales. (Eb6) & $\begin{array}{l}N^{o} \text { de hectáreas de usos industriales } \\
\text { en la zona inundable. }\end{array}$ & SIOSE \\
\hline & & \multicolumn{2}{|c|}{ Usos residenciales y de servicios. (Eb7) } & $\begin{array}{l}N^{o} \text { de hectáreas de superficie } \\
\text { residencial o de servicios en la } \\
\text { zona inundable. }\end{array}$ & SIOSE \\
\hline & & \multicolumn{2}{|c|}{ Usos de infraestructuras y equipamientos. (Eb8) } & $\begin{array}{l}N^{o} \text { de hectáreas de superficie de } \\
\text { infraestructuras y equipamientos en } \\
\text { la zona inundable. }\end{array}$ & SIOSE \\
\hline & & \multicolumn{2}{|c|}{ Usos de zonas protegidas y patrimoniales. (Eb9) } & $\begin{array}{l}N^{o} \text { de hectáreas de zonas protegidas } \\
\text { y elementos patrimoniales en la } \\
\text { zona inundable. }\end{array}$ & SIOSE \\
\hline \multirow{6}{*}{ 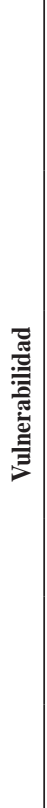 } & \multirow{6}{*}{$\begin{array}{l}\text { Interrupción } \\
\text { de servicios } \\
\text { territoriales } \\
\text { básicos. }\end{array}$} & \multirow{3}{*}{$\begin{array}{l}\text { Servicios } \\
\text { básicos } \\
\text { interrumpidos } \\
\text { por inundación } \\
\text { o aislamiento } \\
\text { (Vpe1) }\end{array}$} & $\begin{array}{l}\text { Servicio de socorro y asistencia } \\
\qquad(\mathrm{Vp} 1.1)\end{array}$ & $\begin{array}{l}\text { Instalaciones de bomberos, } \\
\text { policía, guardia civil, ambulancias } \\
\text { (hospitales y centros de salud) y } \\
\text { cruz roja afectados por inundación } \\
\text { o aislamiento. }\end{array}$ & $D E R A$ \\
\hline & & & $\begin{array}{l}\text { Equipamientos y servicios básicos } \\
\qquad(\text { Vp 1.2) }\end{array}$ & $\begin{array}{l}\text { Hospitales, centros de salud, } \\
\text { centros educativos, centros Adm. } \\
\text { Pública (comisarias, etc.) afectados } \\
\text { por inundación o aislamientos. }\end{array}$ & $D E R A$ \\
\hline & & & $\begin{array}{l}\text { Infraestructuras de transporte. } \\
\qquad(\mathrm{Vp} 1.3)\end{array}$ & $\begin{array}{l}\text { Aeropuertos, puertos, autovías/ } \\
\text { autopistas, vías férreas, carreteras } \\
\text { afectadas por inundación o } \\
\text { aislamientos, gradados según su } \\
\text { nivel de alcance (local, regional, } \\
\text { nacional o internacional). } \\
\end{array}$ & DERA \\
\hline & & \multirow{2}{*}{$\begin{array}{l}\text { Intensidad } \\
\text { de tráfico } \\
\text { interrumpido. } \\
\text { (Vpe2) }\end{array}$} & IMD afectada. $(\operatorname{Vp} 2.1)$ & $\begin{array}{l}\text { Intensidad Media Diaria de } \\
\text { Vehículos }(I M D) \text { interrumpida. }\end{array}$ & DERA \\
\hline & & & $\begin{array}{c}\text { Población afectable por interrupción } \\
\text { del tráfico. }(\operatorname{Vp} 2.2)\end{array}$ & $\begin{array}{l}\text { Número de habitantes susceptibles } \\
\text { de quedar aislados por } \\
\text { interrupción del tráfico }\end{array}$ & E.P. \\
\hline & & \multicolumn{2}{|c|}{$\begin{array}{c}\text { Servicios de abastecimiento y saneamiento } \\
\text { interrumpidos. }(\operatorname{Vp} 3)\end{array}$} & $\begin{array}{l}\text { Redes de abastecimientos y } \\
\text { saneamientos afectados por } \\
\text { inundación o aislamiento. }\end{array}$ & DERA \\
\hline
\end{tabular}


Tabla 1

RESUMEN DE VARIABLES Y FUENTES EMPLEADAS EN EL DESARROLLO DEL CATÁLOGO CARTOGRÁFICO

\begin{tabular}{|c|c|c|c|c|}
\hline \multicolumn{2}{|r|}{ Bloque temático } & Mapas & Variables & Fuentes \\
\hline \multirow{13}{*}{ 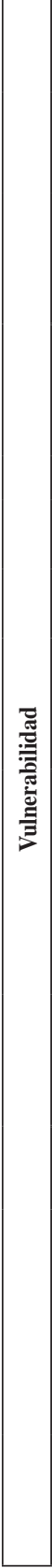 } & \multirow{3}{*}{$\begin{array}{l}\text { Aislamiento de la } \\
\text { población. } \\
\text { (Vp 4) }\end{array}$} & Población aislada en zonas inundables. (Vp 4.1) & $\begin{array}{l}N^{o} \text { de habitantes dentro de la } \\
\text { zona inundable según su grado de } \\
\text { aislamiento. }\end{array}$ & $\begin{array}{c}\text { E.P., } \\
\text { DERA }\end{array}$ \\
\hline & & $\begin{array}{l}\text { Población aislada fuera de zonas inundables. } \\
\qquad(\operatorname{Vp} 4.2)\end{array}$ & $\begin{array}{l}N^{o} \text { de habitantes aislados fuera de la } \\
\text { zona inundable, según su grado de } \\
\text { aislamiento. }\end{array}$ & $\begin{array}{c}\text { E.P., } \\
\text { DERA }\end{array}$ \\
\hline & & $\begin{array}{c}\text { Centros de trabajo aislados V(p 4.3) fuera del } \\
\text { área inundable }\end{array}$ & $\begin{array}{l}N^{o} \text { de hectáreas de servicios e } \\
\text { industrias aisladas fuera del área } \\
\text { inundable, según su grado de } \\
\text { aislamiento. }\end{array}$ & $\begin{array}{l}\text { E.P., } \\
\text { SIOSE }\end{array}$ \\
\hline & \multirow{5}{*}{$\begin{array}{l}\text { Especiales } \\
\text { necesidades } \\
\text { de socorro y } \\
\text { asistencia } \\
\quad \text { (Vp 5) }\end{array}$} & \multirow[t]{2}{*}{$\begin{array}{l}\text { Rescate. } \\
\text { (Vp 5.1) }\end{array}$} & $\begin{array}{l}\text { Colegios de primaria, guarderías, } \\
\text { centros de ancianos centros de } \\
\text { educación especial, centro asistenciales } \\
\text { discapacidad, etc. afectados }\end{array}$ & DERA \\
\hline & & & Edificios sin azoteas y una sola planta & $D G C$ \\
\hline & & Asistencia técnica.(Vp 5.2) & $\begin{array}{l}\text { Edificios y viviendas con sótanos } \\
\text { (bombeo) }\end{array}$ & $D G C$ \\
\hline & & Vigilancia.(Vp 5.3) & $\begin{array}{l}\text { Centros comerciales más susceptibles } \\
\text { de saqueo }\end{array}$ & DERA \\
\hline & & $\begin{array}{l}\text { Socorro y asistencia } \\
\text { a población crítica. } \\
\qquad \text { (Vp 5.4) }\end{array}$ & $\begin{array}{l}\text { Isócronas de tiempo de respuesta de } \\
\text { los servicios de socorro y asistencia a } \\
\text { las zonas con especiales necesidades } \\
\text { de asistencia. }\end{array}$ & $\begin{array}{l}\text { E.P., } \\
\text { SIOSE }\end{array}$ \\
\hline & \multirow[t]{2}{*}{$\begin{array}{l}\text { Población con } \\
\text { conductas } \\
\text { inseguras } o \\
\text { arriesgadas. }\end{array}$} & $\begin{array}{l}\text { Población con carencias informativas sobre la } \\
\text { crisis (Vp 6) }\end{array}$ & $\begin{array}{l}\text { Grupos de población con dificultades } \\
\text { de comunicación: inmigrantes, } \\
\text { turistas (hoteles), colegios } \\
\text { extranjeros, urbanizaciones con } \\
\text { población extranjera, residentes } \\
\text { extranjeros en viviendas aisladas, etc. }\end{array}$ & $\begin{array}{c}\text { E.P., } \\
\text { DERA }\end{array}$ \\
\hline & & $\begin{array}{l}\text { Rutas de tránsito necesario durante la crisis } \\
\qquad(V p 7)\end{array}$ & $\begin{array}{l}\text { Rutas de acceso/salida de colegios, } \\
\text { centros de población dependiente } \\
\text { (ancianos y discapacitados), parkings } \\
\text { y/o centros de trabajo. }\end{array}$ & $\begin{array}{c}E . P ., \\
D E R A\end{array}$ \\
\hline & \multirow{3}{*}{$\begin{array}{l}\text { Afecciones } \\
\text { a bienes } \\
\text { especialmente } \\
\text { sensibles }\end{array}$} & $\begin{array}{l}\text { Bienes de especial valor para la comunidad. } \\
\qquad(V p 8)\end{array}$ & $\begin{array}{l}\text { Bienes de interés patrimonial } \\
\text { (cultural, natural o identitario) }\end{array}$ & DERA \\
\hline & & \multirow[t]{2}{*}{$\begin{array}{l}\text { Bienes singularmente frágiles } \\
\qquad(V p 9)\end{array}$} & $\begin{array}{l}\text { Edificaciones de construcción } \\
\text { precaria o en mal estado de } \\
\text { conservación, y/o con sótano, } \\
\text { y/o disposición transversal a la } \\
\text { dirección del flujo; construcciones no } \\
\text { permanentes (mercadillos, kioscos, } \\
\text { etc.) }\end{array}$ & E.P., $D G C$ \\
\hline & & & $\begin{array}{l}\text { Automóviles estacionados en } \\
\text { aparcamientos subterráneos y/o en } \\
\text { superficie (colindantes con cauces o } \\
\text { en el propio cauce) }\end{array}$ & $\begin{array}{l}\text { E.P., } \\
\text { DERA }\end{array}$ \\
\hline
\end{tabular}


Tabla 1

RESUMEN DE VARIABLES Y FUENTES EMPLEADAS EN EL DESARROLLO DEL CATÁLOGO CARTOGRÁFICO

\begin{tabular}{|c|c|c|c|c|}
\hline \multicolumn{2}{|c|}{ Bloque temático } & Mapas & \multirow{2}{*}{\begin{tabular}{|l|}
\multicolumn{1}{|c|}{ Variables } \\
$\begin{array}{l}\text { Mobiliario urbano (contenedores de } \\
\text { basura, vallas publicitarias, etc.). }\end{array}$ \\
\end{tabular}} & \multirow{2}{*}{$\begin{array}{c}\text { Fuentes } \\
\text { E.P., } \\
D E R A\end{array}$} \\
\hline \multirow{17}{*}{ 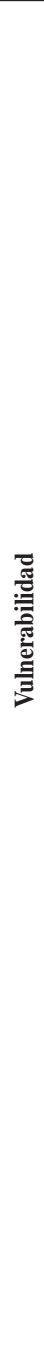 } & \multirow{3}{*}{$\begin{array}{l}\text { Afecciones } \\
\text { a bienes } \\
\text { especialmente } \\
\text { sensibles }\end{array}$} & \multirow{3}{*}{$\begin{array}{l}\text { Bienes singularmente frágiles } \\
\qquad(\operatorname{Vp} 9)\end{array}$} & & \\
\hline & & & $\begin{array}{l}\text { Cultivos de huerta, ganadería } \\
\text { estabulada, invernaderos, etc. }\end{array}$ & E.P. \\
\hline & & & $\begin{array}{l}\text { Viales con especiales problemas } \\
\text { de drenaje (remanso del flujo } \\
\text { de inundación, problemas de } \\
\text { alcantarillado) }\end{array}$ & $\begin{array}{l}E . P ., \\
D E R A\end{array}$ \\
\hline & \multirow{3}{*}{\multicolumn{2}{|c|}{$\begin{array}{l}\text { Zonas sensibles a la contaminación y otros riesgos asociados. (Vp } \\
10)\end{array}$}} & $\begin{array}{l}\text { Espacios naturales protegidos (ENP, } \\
\text { ZEPA, LIC, ZEPIM). }\end{array}$ & $D E R A$ \\
\hline & & & $\begin{array}{l}\text { Captaciones de aguas para el } \\
\text { consumo humano y/o industria }\end{array}$ & $\begin{array}{l}\text { P.H.D. } \\
\text { H.M. }\end{array}$ \\
\hline & & & Zonas recreativas dedicadas al baño & DERA \\
\hline & \multirow{6}{*}{$\begin{array}{l}\text { Elevado coste de } \\
\text { reposición de las } \\
\text { pérdidas. }(\text { Vr } 11)\end{array}$} & \multirow{2}{*}{$\begin{array}{l}\text { Potencial de pérdida económica agraria. } \\
\qquad(\operatorname{Vr} 11.1)\end{array}$} & $\begin{array}{l}N^{o} \text { de hectáreas y tipo de cultivo } \\
\text { afectados por la inundación. }\end{array}$ & E.P., DGC \\
\hline & & & $\begin{array}{l}\text { Estimación de pérdidas económicas } \\
\text { potenciales (según extensión y tipo } \\
\text { de cultivo) }\end{array}$ & $E . P ., D G C$ \\
\hline & & \multirow[b]{2}{*}{$\begin{array}{l}\text { Potencial de pérdida económica de } \\
\text { viviendas. }(\operatorname{Vr} 11.2)\end{array}$} & $\begin{array}{l}\text { Número de metros cuadrados de } \\
\text { vivienda afectados por la inundación }\end{array}$ & E.P., DGC \\
\hline & & & $\begin{array}{l}\text { Estimación de pérdidas económicas } \\
\text { potenciales (según la calidad y } \\
\text { extensión de la vivienda y sus costes } \\
\text { medios de construcción) }\end{array}$ & $E . P ., D G C$ \\
\hline & & \multirow{2}{*}{$\begin{array}{l}\text { Potencial de pérdida económica de } \\
\text { vehículos. }(\operatorname{Vr} 11.3)\end{array}$} & $\begin{array}{l}N^{o} \text { de vehículos estacionados en } \\
\text { aparcamientos de la zona inundable. }\end{array}$ & E.P., DGC \\
\hline & & & $\begin{array}{l}\text { Estimación de pérdidas económicas } \\
\text { (según coste medio de mercado) }\end{array}$ & E.P., DGC \\
\hline & \multirow{5}{*}{$\begin{array}{l}\text { Dificultad de la } \\
\text { población para la } \\
\text { recuperación frente } \\
\text { a la pérdida. }\end{array}$} & \multirow{3}{*}{$\begin{array}{l}\text { Nivel socio-económico de la población } \\
\text { residente en el área inundable (Vr 12) }\end{array}$} & Nivel de paro & AVUE \\
\hline & & & Indicadores de delincuencia & $A V U E$ \\
\hline & & & $\begin{array}{l}\text { Indicadores de calidad de la } \\
\text { vivienda: viviendas con menos de } \\
30 m^{2} \text {, sin servicios ni aseos, otros }\end{array}$ & AVUE \\
\hline & & \multirow{2}{*}{$\begin{array}{l}\text { Capacidad de resiliencia de la población } \\
\text { residente en área inundable. (Vr 13) }\end{array}$} & Nivel socio-económico & E.P., AVUE \\
\hline & & & Estado de conservación de la vivienda & AVUE \\
\hline
\end{tabular}

Fuentes:

DERA: Datos Espaciales de Referencia de Andalucía 2016

EHCB: Estudio hidráulico para la prevención de inundaciones y la ordenación de la cuenca del río Bárbate. Dirección General de Planificación y Gestión del Dominio Público Hidráulico, Consejería de Medio Ambiente y Ordenación del Territorio, Junta de Andalucía. Año 2014

SIOSE: Sistema de Información sobre Ocupación del Suelo de España. Año 2016

E.P.: Elaboración propia. Año 2016

DGC: Dirección General de Catastro. Año 2016

P.H.D.H.M.: Plan Hidrológicos de la Demarcación Hidrográfica del Mediterráneo. Año 2010

AVUE: Atlas de Vulnerabilidad Urbana de España. Año 2016 


\section{EJEMPLOS DE APLICACIÓN DE LA CARTOGRAFÍA DE VULNERABILIDAD PROPUESTA AL ÁREA INUNDABLE DEL BAJO GUADALHORCE (MÁLAGA)}

Se incluyen a continuación varios ejemplos de los resultados obtenidos de la aplicación de la metodología propuesta en un contexto inundable próximo a la ciudad de Málaga. El Bajo Guadalhorce es un estuario colmatado con dificultades de drenaje propias de su configuración topográfica y dinámica geomorfológica. Sobre este espacio situado en el límite occidental de la ciudad de Málaga, y por tanto en su espacio de expansión urbanística, el río ha aportado tanto potencialidades como peligros. A lo largo de la historia se han dado distintos procesos de ocupación humana, con patrones territoriales y usos del suelo de intensidad variable, y mayor o menor grado de adaptación al carácter estructuralmente inundable del espacio (Perles et al, 1999, a, b, c, d). Tras el episodio de inundación de 1989, especialmente grave, se procedió a la aplicación de medidas de estructurales sobre la peligrosidad como vía para control del problema, y se construyó en desembocadura un extenso tramo de encauzamiento del río. A pesar de que la zona ha seguido experimentando inundaciones, este hecho dio pie a construir una imagen del área inundable como espacio seguro. A partir de esta idea, el planeamiento urbanístico ha ido consolidando la zona como un espacio de denso crecimiento de la ciudad, y permitido el avance no sólo del uso residencial, sino también de centros comerciales, grandes instalaciones deportivas de uso recreativo que concitan aglomeraciones de distinto tipo (conciertos, certámenes deportivos), consolidación de polígonos industriales y ampliación de las instalaciones del aeropuerto de Málaga. El riesgo en la zona, en consecuencia, ha ido aumentando generado por el extraordinario aumento de la exposición, y por la ausencia de medidas de disminución de la vulnerabilidad y adaptación a las condiciones de riesgo en los espacios que se han ido construyendo. A continuación se muestran ejemplos de algunos de los mapas propuestos en el catálogo cartográfico de vulnerabilidad aplicados a esta zona inundable.

\section{Mapa Vp 1.2:}

Infraestructuras de transporte afectadas por inundación o aislamiento según su ámbito de acción (local/ regional/ internacional). Detalle del área inundable del río Guadalhorce (Málaga).

En el mapa correspondiente a la posible afectación de las infraestructuras de transporte del territorio por la inundación o el aislamiento (Figura 1) puede observarse como, en el entorno de la desembocadura del río Guadalhorce, la densidad de tramos de infraestructuras afectadas es elevada, y la vulnerabilidad se eleva en razón del ámbito internacional de los servicios prestados en el caso del aeropuerto internacional de Málaga. Son varios los puntos de potencial interrupción de las infraestructuras de transporte, tanto viarias (tramos de la nacional 340 y del ferrocarril de cercanías Málaga-Fuengirola), como de tráfico aéreo, con afección de parte de las instalaciones del aeropuerto internacional de Málaga, tanto en el sector de las pistas de aterrizaje, como en el de otros sectores y edificaciones. 


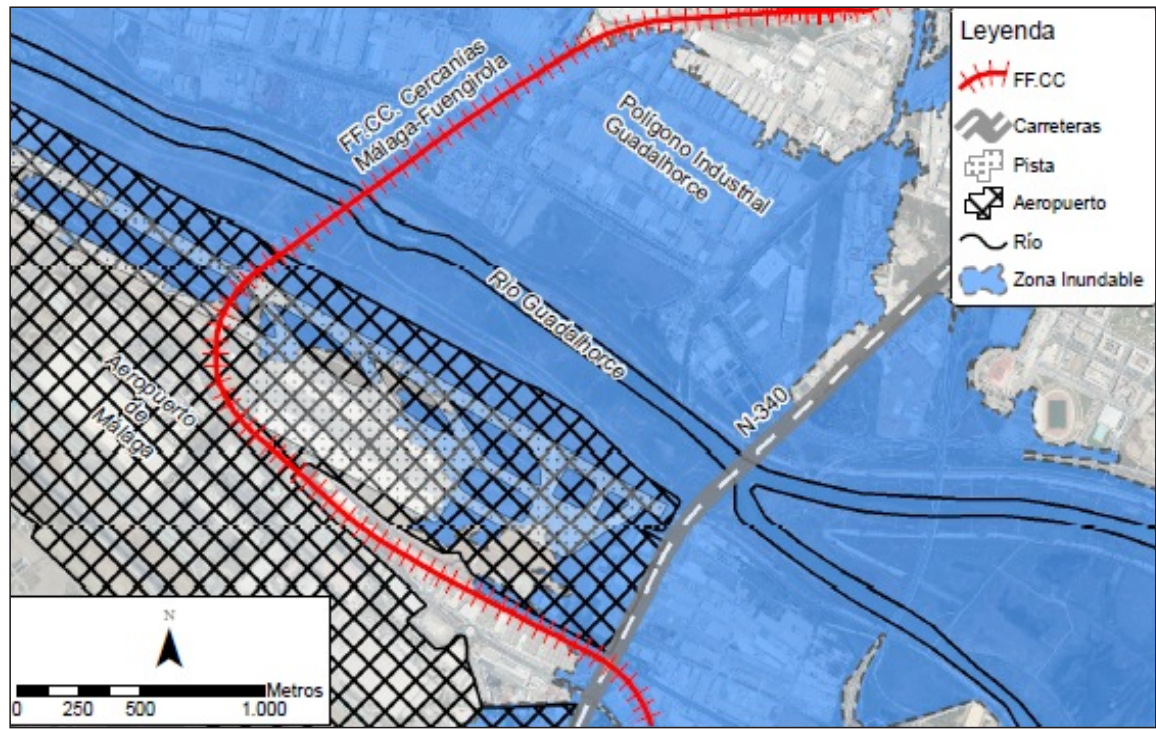

Fuentes: Consejería de Medio Ambiente y Ordenación del Territorio Junta de Andalucía, DERA.

Mapa: elaboración propia.

Mapa Vp 4.2: Población fuera del área inundable susceptible de quedar aislada por cortes en las carreteras de acceso, según su grado de aislamiento. Detalle del área inundable del río Guadalhorce (Málaga).

En el mapa se representa el caso del núcleo de El Tarajal, situado en el Bajo Guadalhorce (Figura 2). El núcleo, situado en un suave resalte topográfico no es afectado por la lámina de agua de forma directa, pero sin embargo, según se muestra en la cartografía, un total de 800 personas quedan potencialmente aisladas por cortes en las infraestructuras viarias, que llegan a impedir el acceso al núcleo de forma total. La vulnerabilidad de la zona frente al problema del aislamiento, en consecuencia, es alta.

A partir del ejemplo de la población de Zapata, situada en el Bajo Guadalhorce (Figura 3), el mapa recoge los sectores del territorio con más necesidades potenciales de socorro en formas diversas; se han previsto necesidades potenciales de rescate para el caso de la población dependiente de edad infantil, localizada en la escuela primaria afectada por la lámina de inundación, y las zonas de viviendas sin posibilidad de refugio de la población en una segunda planta de la vivienda. De igual modo, se han identificado como áreas potenciales de asistencia (bombeo) las viviendas con sótanos situadas sobre la lámina de inundación. Los elementos han sido gradados en razón de la accesibilidad que los servicios de asistencia tendrían a estos puntos de reclamo. 
Figura 2

MAPA VP 4.2 .

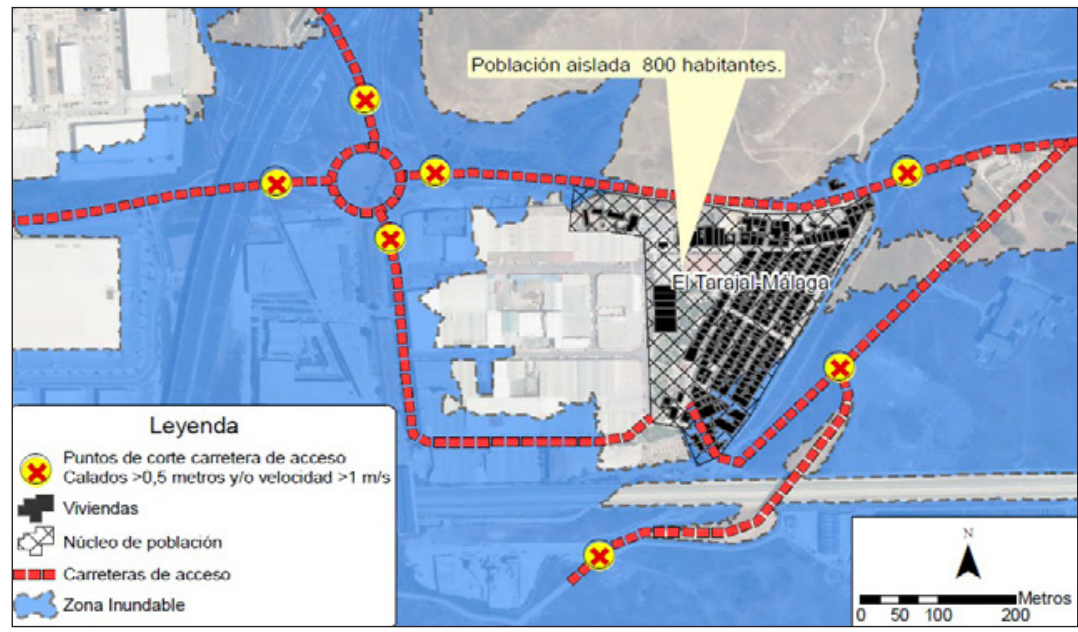

Fuentes: Consejería de Medio Ambiente y Ordenación del Territorio Junta de Andalucía, DERA, Catastro (DGC). Mapa: elaboración propia.

Mapa Vp5: Sectores del territorio con especiales necesidades potenciales de socorro (rescate, asistencia y vigilancia) gradados según su accesibilidad a estos servicios. Detalle del área inundable del río Guadalhorce (Málaga).

Figura 3

MAPA VP5.

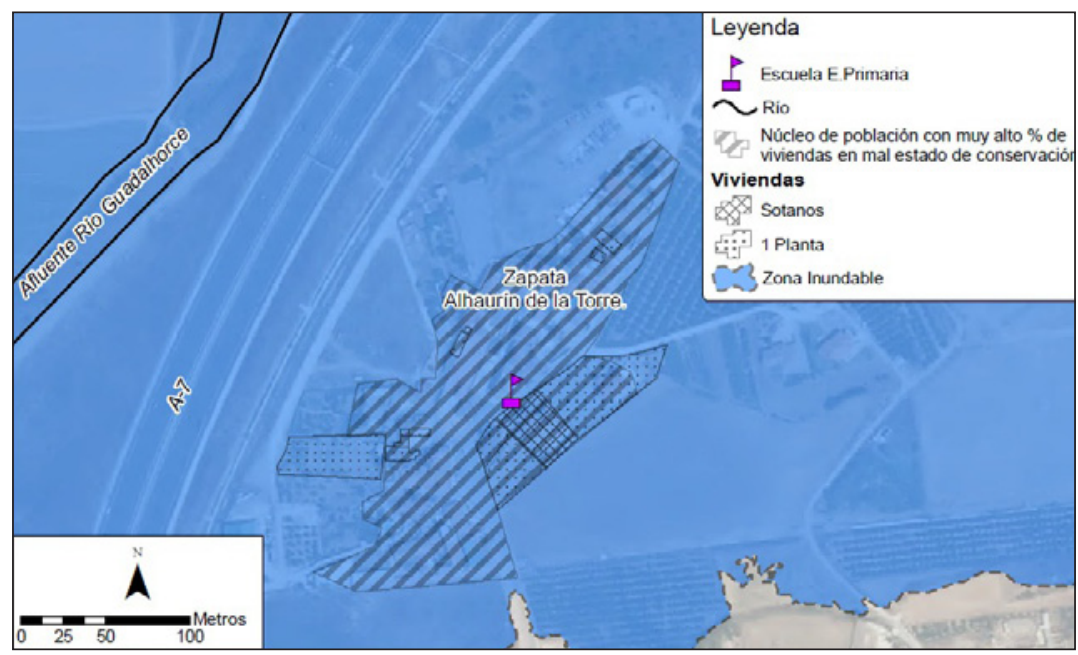

Fuentes: Consejería de Medio Ambiente y Ordenación del Territorio Junta de Andalucía, DERA, Catastro (DGC). Mapa: elaboración propia. 


\section{Mapa Vp 7: Trayectos del viario con alta vulnerabilidad (alta concentración de tránsito) durante los momentos de máxima alerta y peligrosidad. Detalle del área inundable del río Guadalhorce (Málaga).}

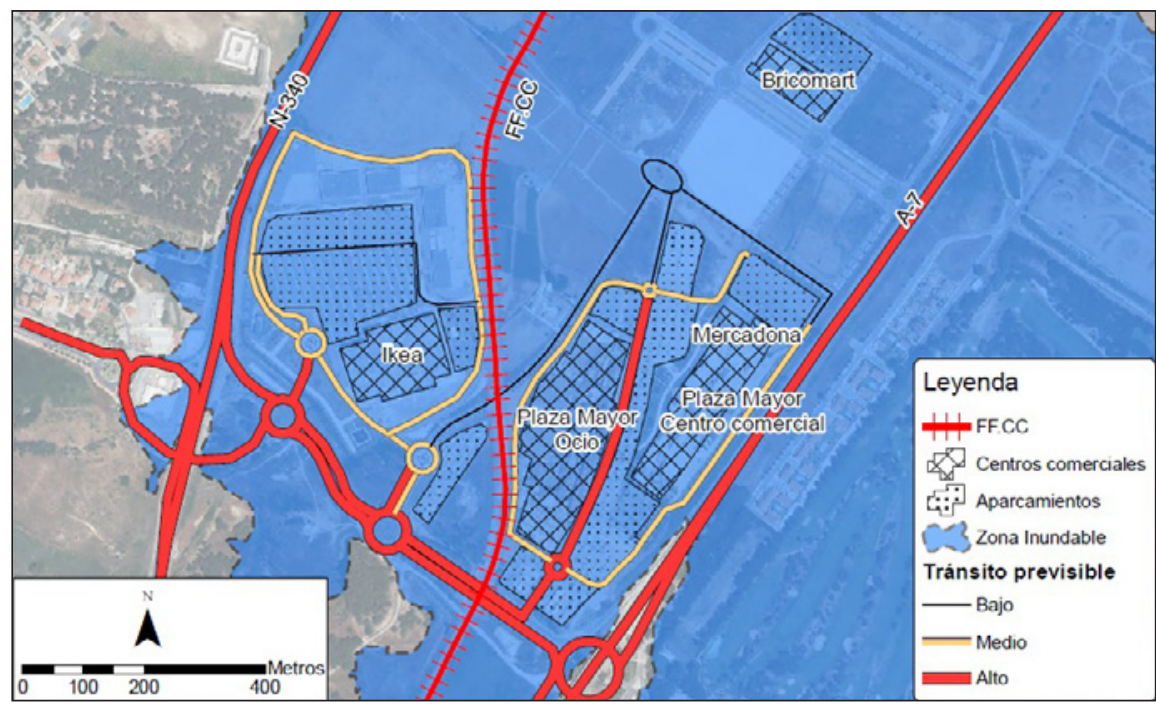

Fuentes: Consejería de Medio Ambiente y Ordenación del Territorio Junta de Andalucía, DERA. Mapa: elaboración propia.

El mapa Vp 7 representa un sector comercial y de ocio, situado en el área inundable del río Guadalhorce (Figura 4). En la cartografía se han identificado tramos del viario que constituyen puntos de alta vulnerabilidad durante los momentos de crisis de la inundación, ya que son las vías de salida desde puntos de alta concentración de población por motivos funcionales, como es el caso de los grandes centros comerciales y las zonas de parking asociadas a ellos, hacia las principales carreteras de evacuación. Este proceso de salida simultánea y masiva en momentos de alerta de inundación, propicia la concentración de automóviles en el viario periférico, y en los parkings del entorno, generando situaciones de alta vulnerabilidad (bloqueos de tráfico, exposición del automóvil o la persona a zonas de flujos rápidos, etc.). En el ejemplo cartográfico, la alta concentración de centros comerciales y de ocio, y el grado de inundabilidad del entorno permite prever potenciales situaciones de crisis de diversas índoles.

La Directiva Europea de Inundaciones (60/2007) y la normativa estatal y autonómica derivada de ella precisa que la inundación debe contemplarse como un vector de transferencia de otros posibles riesgos como pueda ser el de contaminación y movimientos en masa entre otros. El mapa muestra un ejemplo de cómo la inundación de un sector del territorio con potencial contaminante (los tanques de residuos de depuración de la EDAR del Guadalhorce) genera a partir de ese punto peligro de contaminación, frente al que es necesario observar la vulnerabilidad, no siempre coincidente con la vulnerabilidad frente a la inunda- 
ción (Figura 5). Este es el caso de la ZEPA de Desembocadura del Guadalhorce, un paraje de humedal protegido, escasamente vulnerable frente a la propia inundación, que sin embargo si muestra una muy elevada vulnerabilidad frente al posible flujo de agua contaminada.

\section{Mapa Vp 10: Usos del suelo especialmente sensibles frente a aguas de inundación conta- minadas, o frente a otros peligros asociados a la inundación. Detalle del área inundable del río Guadalhorce (Málaga).}

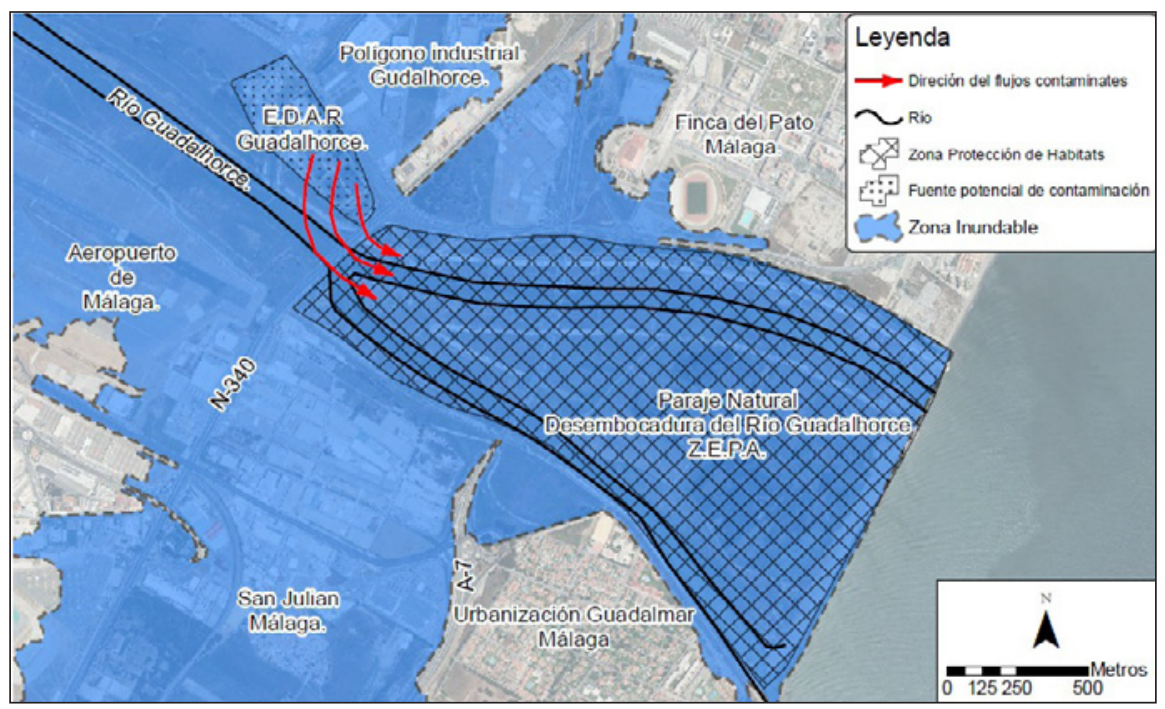

Fuentes: Consejería de Medio Ambiente y Ordenación del Territorio Junta de Andalucía, DERA.

Mapa: elaboración propia.

\section{CONCLUSIONES}

La cartografía de vulnerabilidad constituye una herramienta clave para la puesta en marcha de soluciones al problema de la inundación, problema que muestra una tendencia al incremento en intensidad en próximos escenarios de cambio climático y extensión del proceso urbanizador. Por otra parte, más allá de la oportunidad de aplicar medidas preventivas sobre la peligrosidad para evitar la generación de daños en las zonas de futura expansión urbanística, la realidad territorial de la mayor parte de los países muestra problemas de inundación en zonas ya consolidadas, donde el riesgo es sobrevenido, y en las que la principal vía de actuación es la disminución de la vulnerabilidad en un territorio ya inevitablemente expuesto. La aplicación de los Planes de Gestión del Riesgo de Inundación en el ámbito de la los Planes de Ámbito Local constituye una oportunidad inédita para consolidar de forma efectiva la propuesta de medidas de mitigación sobre la vulnerabilidad, y resaltar la importancia que la vulnerabilidad tiene en la producción de la catástrofe. 
La puntualización de contenidos y términos implicados en el concepto de vulnerabilidad del territorio frente a la inundación, y la precisión de los cometidos que puede desempeñar la cartografía de vulnerabilidad en el ámbito aplicado es un asunto que necesariamente debe ser resuelto y consensuado en el ámbito de la reflexión científica y académica, para poder acometer con rigor la fase de gestión y aplicación de medidas de mitigación sobre la vulnerabilidad. En caso de que el procedimiento de evaluación de la vulnerabilidad en cada ARPS se elabore de forma autónoma bajo distintos criterios técnicos en cada una de las ARPs invalida el potencial de la herramienta.

El catálogo cartográfico propuesto en este trabajo ha aportado criterios de reflexión científica en la conceptuación, coherencia en el tránsito entre la teoría y la aplicación, y un marcado sentido aplicado a la resolución de los problemas de vulnerabilidad del territorio frente a la inundación. Respecto a trabajos anteriores, aporta una visión transversal que aúna propuestas provenientes de distintas concepciones de la vulnerabilidad, atendiendo a factores de vulnerabilidad física, conductual, contextual y territorial de la población y sus bienes. Se proponen documentos cartográficos concretos, para abordar cada problema de vulnerabilidad identificado, y se utilizan para ello aspectos del medio físico y del medio humano, siempre vinculados y matizados por la posición en el territorio de los distintos elementos. El catálogo se muestra por tanto como una herramienta sintética, completa y versátil, a la vez que útil y aplicable para la búsqueda de soluciones al impacto de las inundaciones.

\section{AGRADECIMIENTOS}

El presente artículo se fundamenta en los contenidos del Proyecto de Investigación Patrón territorial y vulnerabilidad social frente al riesgo de inundación. Metodologías de evaluación y cartografía de la vulnerabilidad social adaptadas a la nueva Ley de Aguas de Andalucía (P10-SEJ-6835-R), financiado por la Consejería de Innovación, Ciencia y Empresa de la Junta de Andalucía.

\section{BIBLIOGRAFÍA}

ADGER, W.M. (2006): "Vulnerability". Global Environmental Change, 16 (3), 268-281.

ÁLVAREZ, I. y CADENA, E. (2006): "Índice de Vulnerabilidad Social en los Países de la OCDE". Universidad Autónoma de Madrid. Economic Analysis Working Paper Series. I.S.S.N: 1885-6888.

AROCA-JIMENEZ, E., BODOQUE, J.M., GARCÍA, J.A. y DIEZ-HERRERO, A. (2016):

"Análisis de vulnerabilidad social ante avenidas súbitas en zonas urbanas de Castilla y León (España)". Comunicaciones al XIV Reunión Nacional de Geomorfología, pp. 283-290.

BALICA, S.F., DOUBEN, N. y WRIGHT, N.G. (2009): "Flood vulnerability indices at varying spatial scales". Water Science \& Technology, 60(10) 2571-2580.

BARBAT, A., CARREÑO, M., CARDONA, O. y MARULANDA, M. (2011): "Holistic assessment of seismic risk in Urban areas (Evaluación holística del riesgo sísmico en zonas Urbanas)". Revista Internacional de Métodos Numéricos para Cálculo y Diseño en Ingeniería. 27: 3-27. 
BARROCA, B., BERNARDARA, P., MOUCHEL, J.M. y HUBERT, G. (2006): “Indicators for identification of urban flooding vulnerability". Nat. Hazards Earth Syst. Sci. 6, 553-561.

BESCOS, A. y CAMARASA, A.M. (2004): "La creciente ocupación antrópica del espacio inundable y el aumento de la vulnerabilidad en las poblaciones del Bajo Arga (Navarra)". Boletín de la Asociación de Geógrafos Españoles, 37, 101-117.

BIRKMANN, J. (Ed.) (2006): Measuaring vulnerability to natural hazards: towards disaster resilient society. New York, NY: United Nations University.

BIRKMANN, J. y WISNER, B. (Ed.) (2006): Measuring the Un-measurable The Challenge $o f$. UNU-EHS SOURCE.

BIRKMANN, J. (2007): "Risk and vulnerability indicators at different scales: applicability, usefulness and policy implications". Environmental Hazards, 7(1), 20-31.

BIRKMANN, J., CARDONA, O., CARREÑO, M., BARBAT, A., PELLING, M., SCHNEIDERBAUER, S., KIENBERGER, S., KEILER, M., ALEXANDER, D., ZEIL, P. y WELLE, T. (2014): "Theoretical and Conceptual Framework for the Assessment of Vulnerability to Natural Hazards and Climate Change in Europe". In Assessment of Vulnerability to Natural Hazards. A European Perspective. Edited by Jörn Birkmann, Stefan Kienberger and David E. Alexander. Chapter I, pp. 1-20.

BLAIKIE, P., CANNON, T., DAVIS, I., y WISNER, B. (1994): “At Risk: Natural Hazards People's Vulnerability and Disasters”. 284 pp. 1994. London, Routledge.

BOLLIN, C. y HIDAJAT, R. (2006): “Community -based risk index: Pilot implementation in Indonesia". In Measuring Vulnerability to Natural Hazards. Towards disaster resilient societies (ed. BIRKMANN J.), pp. 271-289. United Nations University Press, New York, USA.

BURTON, I., KATES, R.W. y WHITE, G.F. (1978): The environment as hazard. Oxford University Press, 240 p., New York.

CALVO GARCÍA-TORNELL (1984): La Geografía de los riesgos. Cuadernos críticos de Geografía Urbana. Barcelona.

CALVO GARCÍA-TORNELL (2001): Sociedades y territorios en riesgo. Ediciones del Serbal. Barcelona.

CAMARASA BELMONTE, A.M., LOPÉZ-GARCÍA, M.J. y SORIANO GRACÍA, J. (2008): Cartografía de vulnerabilidad frente a inundaciones en llanos mediterráneos. Caso de estudio del Barranc de Carraixet y Rambla de Poyo. Universidad de Alcalá. Servicio de Publicaciones.

CARDONA, O. (2003): "La necesidad de repensar de manera holística los conceptos de vulnerabilidad y riesgo. Una crítica y una revisión necesaria para la gestión”. International Work-Conference on Vulnerability in Disaster Theory and Practice, Holanda. http:// www.desenredando.org/public/articulos/2003/rmhcvr/rmhcvr_may-08-2003.pdf

CARDONA, O. y VAN AALST, M. (2012): "Determinants of risk: exposure and vulnerability". In: Fiel CB, Barros V. Stocker TF et al (Eds.) Managing the Risks of Extreme Events and Disasters to Advance Climate Change Adaptation. A Special Report if Working Groups I and II of the Intergovernmental Penel on Climate Change (IPCC). Cambridge and New York: Cambridge University Press, pp. 65-108. 
CARREÑO, O., BARBAT, A. y CARDONA, O. (2014): "Holistic Evaluation of the Seismic Risk in Barcelona by Using Indicators. In Assessment of Vulnerability to Natural Hazards. A European Perspective. Edited by Jörn Birkmann, Stefan Kienberger and David E. Alexander. Chapter II, pp. 21-52.

CASTILLO LÓPEZ, O. (2016): Caracterización hidromorfológica y riesgos de inundación en la cuenca fluvial del río Guadiaro (Cádiz y Málaga). Tesis Doctoral, Universidad de Cádiz.

CLARK, G.E., MOSER, S.C., RATICK, S.J., DOW, K., MEYER, W.B., EMANI, S., JIN, W., KASPERESON, J.X., KASPERSON, R.E., y SCHARZ, H.E. (1998): “Assessing the vulnerability of coastal communities to extreme storms: the case of Revere, M A, USA", Mitigation and Adaptation Strategies for Global Change, 3, pp. 59-82.

CON, M., SUSINI, S., CATALÁ, S. y QUINTEROS, S. (2009): Índice de vulnerabilidad social (IVS). Documento metodológico. Informes temáticos de la dirección de investigación y estadística del Ministerio de Educación del GCBA, Argentina.

CUTTER, S., BORUFF, B. y SHIRLEY, W. (2003): "Social vulnerability to environmental hazards", Social Science Quarterly, Vol. 84, n² 2. pp. 242-261.

DIAZ MUÑOZ, M.A. y DIAZ CASTILLO, C. (2002): El análisis de la vulnerabilidad en las cartografía de riesgo tecnológicos. Algunas cuestiones conceptuales y metodológicas. Universidad de Alcalá. Servicio de Publicaciones.

DÍEZ-HERRERO, A., LAIN-HUERTA, L. y LLORENTE-ISIDRO, M. (2008): Mapas de peligrosidad por avenidas e inundaciones. Guía metodológica para su elaboración. Publicaciones del Instituto Geológico y Minero de España, Serie Riesgos Geológicos/

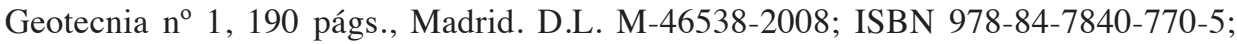
NIPO 657-08-026-2.

DWYER, A., ZOPPOU C., NIELSEN O., DAY S., y ROBERTS, S. (2004): “Quantifying social vulnerability: A methodology for identifying those at risk to natural hazards". Geoscience Australia Record 2004/14.

EAKING, H. y LUERS, A. L. (2006): "Assesing the vulnerability of social-Environmental Systems“. Annual Review of Environment and Resources, 31, pp. 365-394.

EUROPEAN COMISSION (2010): "Risk assessment and mapping guidelines for management".

GAO J., NICKUM, J.E., y PAN, Y. (2007): “An assessment of flood hazard vulnerability in the Dongting Lake Region of China". Lakes \& Reservoirs: Research and Management 12.

GARROTE, J., NAVALUENGO, F.M. y DIEZ-HERRERO, A. (2016): “Quantification of flash flood economic risk using ultra-detailed stage-damage functions 2-D hydraulic models". Journal of Hydrology. In Press, available online 10 February 2016.

HAUSMANN, P. y PERILLS, C. (1999): Inundaciones, ¿Un riesgo asegurable?. Swiss Re Publishing, Zurich.

MASGRAU, L.R., YARNAL, B. y FISHER, A. (2007): "Flood vulnerability and comercial activities: the case of the city of Girona, Spain". Disasters, 26(4), 676-699.

MÁYER SUÁREZ, P. (2000): Riesgos asociados a episodios de lluvia intensa en la ciudad de Las Palmas de Gran Canaria (1869-1999). Tésis de Licenciatura. Universidad de Las Palmas de Gran Canaria. 
MESSNER, F. y MEYER, V. (2005): Flood damage, vulnerability and risk perception -challenges for flood damage research" Leipzig-Halle, Department of Economics. UFZUmwelt for schungszentrum Leipzig-Halle.

OLCINA CANTOS, J. y AYALA CARCEDO, F.J. (2002): "Riesgos naturales. Conceptos fundamentales y clasificación”, en AYALA-CARCEDO, F.J. y OLCINA CANTOS, J. (Eds.) (2002): Riesgos Naturales, Ariel, Barcelona.

OLCINA CANTOS, J. (2008): "Cambios en la consideración territorial, conceptual y de método de los riesgos naturales", Geocrítica, Diez años de cambios en el mundo, en la Geografía y en las ciencias sociales, 1999-2008. http://www.ub.es/geocrit/-xcol/62.htm

PAUCAR CAMACHO, J.A. (2016): Modelo para la articulación de la Gestión del Riesgo en el proceso de Ordenamiento Territorial de la ciudad de Guaranda/Ecuador. Tesis Doctoral. Universidad de Valencia.

PAQUIER, A. (2006): "Los mapas de riesgo de inundación en Francia: usos para la prevención y reglamentación, métodos de análisis y producción cartográfica”. En: Diez, A., Laín, L. y Llorente, M. (Eds.): Mapas de peligrosidad de avenidas e inundaciones. Métodos, experiencias y aplicación. Publicaciones del IGME, Serie Medio Ambiente, Riesgos Geológicos n 7 , Madrid, 17-26 pp.

PARLAMENTO EUROPEO (2006): Directiva 2006/0005 (COD) LEX 802 del Parlamento Europeo y del Consejo relativa a la Evaluación y Gestión de los Riesgos de Inundación. Estrasburgo, 2007.

PENNING-ROWSELL, E.C. y GREEN, C.H. (2000): "New insights into the appraisal of flood alleviation benefits. I. Flood damage and flood loss information". Journal of the Institute of Water Environment Management 14, 347-353.

PERLES, M.J., CABELLO, J., LÓPEZ, C., VALLEJO, J.A. y VÍAS, J.M. (1999): "Propuestas de ordenación para la zona del bajo Guadalhorce: Proyecto de encauzamiento". En: Jábega, $n^{\circ} .82$, pp. 65-79.

PERLES, M.J., CABELLO, J., LÓPEZ, C., VALLEJO, J.A. y VÍAS, J.M. (1999): «Evolución de las relaciones hombre-medio en la desembocadura del Guadalhorce". Jábega, n. 80, pp. 75-88.

PERLES, M.J., CABELLO, J., LÓPEZ, C., VALLEJO, J.A. y VÍAS, J.M. (1999):” El problema inundación-ocupación en el Bajo Guadalhorce". Jábega, no. 81, pp. 62-77.

PERLES ROSELLÓ, M.J. (1999): "El riesgo como construcción social. Vulnerabilidad, adaptación y percepción del riesgo en un área de inundabilidad crónica", Baética, n 21 , pp. 157-175.

PERLES ROSELlÓ, M.J., GALLEGOS REINA, A. y CANTARERO PRADOS, F. (2006): "Análisis del área inundable obtenida mediante una evaluación integrada de la peligrosidad de inundación y peligros asociados" Baética, n 28, pp. 527-545.

PERLES ROSELLÓ, M.J. y CANTARERO PRADOS, F. (2007): "Particularidades de la generación del riesgo en espacios periurbanos", Baética, n 29, 145-153.

PERLES ROSELLÓ, M.J., VÍAS MARTÍNEZ, J. y ANDREO NAVARRO, B. (2008): Vulnerability of human environment to risk: case of groundwater contamination risk". Environment International, Elsevier. DOI: 10.1016/j.envint.2008.08.005

PERLES, M.J. y MÉRIDA, M. (2010): “Patrón territorial y conformación del riesgo en espacios periurbanos. El caso de la periferia Este de la ciudad de Málaga”. Scripta Nova, vol XIV, Barcelona. 
PERLES ROSELLÓ, M.J. (2010): “Apuntes para la evaluación de la vulnerabilidad social frente al riesgo", Baética n ${ }^{\circ} 32$, pp. 67-87.

PITA LÓPEZ, M.F. (Coord.) (1999): Riesgos catastróficos y Ordenación del Territorio en Andalucía. Ed. Consejería de Obras Públicas y Transportes. Junta de Andalucía. Sevilla

RIBAS PALOM, A. (2001): Gestió Integral del Risc d'Inundació. Projecte Rivermed.

RUIZ, M. (2011): Vulnerabilidad territorial y evaluación de daños postcatástrofe: una aproximación desde la geografía del riesgo. Tesis Doctoral, Universidad Complutense de Madrid.

SAURÍ, D. y RIBAS PALOM, A. (1994): "El análisis del riesgo de avenida en las escuelas geográficas anglosajona, francesa y española”. Estudios Geográficos, n 216, p. 481-502.

SAURÍ, D., DUCH, J., ARBUÉS, C. y JIMÉNEZ, C. (2002): Estudi de la vulnerabilidad del patrimoni cultural a les inundacions de la conca del riu Llobregat. Agencia Catalana del Agua. Barcelona.

SAURÍ, D. (2003): “Tendencias recientes en el análisis geográfico de los riesgos ambientales. In. CALVO, F. y CONESA, C. (Dir.). Los procesos de riesgo con origen natural: naturaleza, efectos y estrategias de actuación. Áreas. Revista de Ciencias Sociales, $\mathrm{n}^{\circ} 23$, p. 17-32.

SCHNEIDERBAUER, S. y EHRLICH, D. (2006): "Social levels and hazard (in) dependence in determining vulnerability". In Measuring Vulnerability to Natural Hazards. Towards disaster resilient societies (ed. BIRKMANN J.) United Nations University Press, New York, USA.

TURNER, B., MATSON, P., MCCARTHY, J., CORELL, R., CHRISTENSEN, L., ECKLEY, N., HOVELSRUD-BRODA, G., KASPERSON, J., KASPERSON, R, MARTELLO, M., MATHIESEN, S., NAYLOR, R., POLSKY, C., PULSIPHER, A., SCHILLER, A., SELIN, H., y TYLER, N. (2003): "Illustrating the Coupled Human-Environment System for Vulnerability Analysis: Three Case Studies". Proceedings of the National Acadmy of Sciences of the United States of America 100 (14):8080-8085.

UNESCO-IHE (2009): Flood Vulnerability Indices (FVI).

UNESCO (2013): Flood Risk Management: A Strategic Approach.

VEYRET, Y., BEUCHER, S., y BONNARD, J.Y. (2005): “Risques naturels et territoires”, en Bagf Geographies, 2005-1.

VÍAS MARTÍNEZ, J. M., ANDREO NAVARRO, B., PERLES ROSELLÓ, M. J., CARRASCO CANTOS, F., VADILLO PÉREZ, I. y JIMÉNEZ GAVILÁN, P. (2003.): "The COP method". Vulnerability and risk mapping for the protection of carbonate (karst) aquifers, Unión Europea, 2003, Bruselas (Bélgica), pp. 163-172. ISBN: 92-894-6416-X.

WHITE, G. F. (1974): Natural hazards. Local, national, global, Oxford University Press, 288 p., Oxford.

WISNER B., BLAIKIE P., CANNON T., y DAVIS, I. (2004): At Risk: Natural hazards, People's Vulnerability and Disasters. Routledge, London.

ZOIDO NARANJO, F. (1998): “Geografía y Ordenación del Territorio". Íber. Didáctica de las ciencias sociales. Geografía e Historia, Barcelona: $\mathrm{n}^{\circ} 16$, Nuevas fronteras de los contenidos geográficos, p. 19-31. 